\title{
Cell-Surface Receptors Transactivation Mediated by G Protein-Coupled Receptors
}

\section{Fabio Cattaneo ${ }^{1, \dagger}$, Germano Guerra ${ }^{2, \dagger}$, Melania Parisi ${ }^{1}$, Marta De Marinis ${ }^{1}$, Domenico Tafuri ${ }^{3}$, Mariapia Cinelli ${ }^{4}$ and Rosario Ammendola ${ }^{1, *}$}

1 Department of Molecular Medicine and Medical Biotechnology, School of Medicine, University of Naples Federico II, Naples 80131, Italy; E-Mails: fabio.cattaneo@unina.it (F.C.); melania.parisi@unina.it (M.P.); mar.demarinis@studenti.unina.it (M.D.M.)

2 Department of Medicine and Health Sciences, University of Molise, Campobasso 86100, Italy; E-Mail: germano.guerra@unimol.it

3 Department of Sport Science and Wellness, University of Naples Parthenope, Naples 80133, Italy; E-Mail: tafuri@uniparthenope.it

4 Department of Public Health, School of Medicine, University of Naples Federico II, Naples 80131, Italy; E-Mail: mariapia.cinelli@unina.it

$\dagger$ These authors contributed equally to this work.

* Author to whom correspondence should be addressed; E-Mail: rosario.ammendola@unina.it; Tel.: +39-081-746-3145; Fax: +39-081-746-4359.

External Editor: Jens Schlossmann

Received: 17 July 2014; in revised form: 30 September 2014 / Accepted: 13 October 2014 / Published: 29 October 2014

Abstract: G protein-coupled receptors (GPCRs) are seven transmembrane-spanning proteins belonging to a large family of cell-surface receptors involved in many intracellular signaling cascades. Despite GPCRs lack intrinsic tyrosine kinase activity, tyrosine phosphorylation of a tyrosine kinase receptor (RTK) occurs in response to binding of specific agonists of several such receptors, triggering intracellular mitogenic cascades. This suggests that the notion that GPCRs are associated with the regulation of post-mitotic cell functions is no longer believable. Crosstalk between GPCR and RTK may occur by different molecular mechanism such as the activation of metalloproteases, which can induce the metalloprotease-dependent release of RTK ligands, or in a ligand-independent manner involving membrane associated non-receptor tyrosine kinases, such as c-Src. Reactive oxygen species (ROS) are also implicated as signaling 
intermediates in RTKs transactivation. Intracellular concentration of ROS increases transiently in cells stimulated with GPCR agonists and their deliberated and regulated generation is mainly catalyzed by enzymes that belong to nicotinamide adenine dinucleotide phosphate (NADPH) oxidase family. Oxidation and/or reduction of cysteine sulfhydryl groups of phosphatases tightly controls the activity of RTKs and ROS-mediated inhibition of cellular phosphatases results in an equilibrium shift from the non-phosphorylated to the phosphorylated state of RTKs. Many GPCR agonists activate phospholipase C, which catalyze the hydrolysis of phosphatidylinositol 4,5-bis-phosphate to produce inositol 1,4,5-triphosphate and diacylglicerol. The consequent mobilization of $\mathrm{Ca}^{2+}$ from endoplasmic reticulum leads to the activation of protein kinase $\mathrm{C}$ (PKC) isoforms. PKC $\alpha$ mediates feedback inhibition of RTK transactivation during GPCR stimulation. Recent data have expanded the coverage of transactivation to include Serine/Threonine kinase receptors and Toll-like receptors. Herein, we discuss the main mechanisms of GPCR-mediated cell-surface receptors transactivation and the pathways involved in intracellular responses induced by GPCR agonists. These studies may suggest the design of novel strategies for therapeutic interventions.

Keywords: GPCR; tyrosine kinase receptor; transactivation; cell signaling; reactive oxygen species

\section{Introduction}

Cross-communication between different signaling systems plays a key role to coordinate the plethora of extracellular stimuli to which a cell is subjected under several physiological or pathological conditions. Cell-surface receptors are the key components of these networks and the inter-receptor crosstalk acts as a general signaling mechanism connecting and diversifying signal transduction pathways. The major classes of cell surface transmembrane proteins are tyrosine kinase receptors (RTKs) and G-protein-coupled receptors (GPCRs), which are the largest group of cell-surface seven-transmembrane proteins [1]. RTKs activation is achieved by ligand binding to the extracellular domain, which can induce dimerization of the receptor and, in turn, the autophosphorylation on tyrosine residues within the cytosolic domain with the formation of Src homology 2 (SH2) or phospho-tyrosine binding (PTB) sites [2]. These represent docking sites for the recruitment of SH2-domain-containing proteins or adaptor proteins, which trigger intracellular signaling cascades. Some signaling proteins containing SH2-domains possess intrinsic tyrosine kinase activity (Src kinases), other adaptor proteins utilize their $\mathrm{SH} 2$ and $\mathrm{SH} 3$ domains to mediate interactions with protein involved in signal transduction, as the case of growth factor receptor-bound protein 2 (Grb2) which recruits Son of sevenless (Sos) protein and triggers the Ras pathway, which leads to phosphorylation and activation of the serine-threonine kinase MAPK (Mitogen-activated protein kinase) [2]. Moreover, binding of hepatocyte growth factor (HGF) to c-Met, a member of the RTK family, induces serine phosphorylation of Smads signaling proteins [3]. GPCRs lack intrinsic enzymatic activity and are coupled to heterotrimeric G proteins, which consist of $\mathrm{G} \alpha, \mathrm{G} \beta$ and $\mathrm{G} \gamma$ subunits. Ligand binding stabilizes the occupied GPCR in an active signaling conformation during which the heterotrimeric G-proteins dissociate in GTP-bound G $\alpha$ and G $\beta \gamma$ subunits. These regulate the activity of several enzymes such as adenylate cyclase, phospholipase C (PLC) 
isoforms and kinases, resulting in generation of intracellular second messengers that control cellular functions. Adding to the complexity of $\mathrm{G}$ protein-dependent signaling is the existence of four major members of the $\mathrm{G} \alpha$ subunit family: $\mathrm{G} \alpha_{\mathrm{s}}, \mathrm{G} \alpha_{\mathrm{i}}, \mathrm{G} \alpha_{12 / 13}$ and $\mathrm{G} \alpha_{\mathrm{q}}$, which are responsible for triggering different signaling responses. Currently $20 \mathrm{G} \alpha, 6 \mathrm{G} \beta$ and $11 \mathrm{G} \gamma$ subunits have been identified [4].

The activity of most GPCRs are regulated by GPCR kinases (GRKs) that phosphorylate the $C$-terminal tail of activated GPCRs, preventing further interaction with heterotrimeric G proteins and leading to termination of receptor signaling and receptor desensitization [5]. GPCR phosphorylation also facilitate recruitment of arrestin proteins ( $\beta$-arrestin), which bind to the desensitized receptors allowing endocytosis via clathrin-coated pits [6]. During desensitization and endocytosis, arrestins also act as scaffolding proteins to recruit a series of signaling and regulatory proteins that add spatiotemporal complexity to GPCR functions.

RTKs and GPCRs act in concert to regulate physiological processes and in some cases their effects are synergic whereas in others they antagonize [7]. The activation of GPCRs can stimulate the signaling activity of RTKs connecting the broad diversity of GPCRs with the potent signaling capacities of RTKs. This molecular mechanism is termed transactivation and was first described in Rat-1 fibroblasts stimulated with a number of GPCR agonists, which induced a rapid tyrosine phosphorylation of epidermal growth factor receptor (EGFR) [8]. GPCR-induced EGFR tyrosine phosphorylation is rapid, transient, and comparable with receptor activation by low amounts of EGF [9].

Moreover, recent evidence show that RTKs use a G protein to induce activation of signaling pathways [10], and that several GPCR agonists can transactivate members of the cell surface transforming growth factor (TGF)- $\beta$ receptors superfamily, which possess predominantly Serine/Threonine kinase (S/TK) activity [11], as well as Toll-like receptors (TLRs).

Transactivation of RTKs by GPCRs signaling can occur through different mechanisms. In the ligand-dependent triple-membrane-passing-signal (TMPS) mechanism, GPCR-mediated RTK transactivation depends on activation of membrane-bound matrix metalloproteases (MMPs), such as the A Disintegrin And Metalloprotease (ADAM) family members [9,12]. The ligand-independent mechanism suggests that GPCR stimulation triggers the activation of several second messengers such as $\mathrm{Ca}^{2+}$ ions, protein kinase $\mathrm{C}$ (PKC), the non-receptor protein tyrosine kinases Src and Pyk, $\beta$-arrestin and reactive oxygen species (ROS) which, in turn, induce tyrosine phosphorylation and subsequent activation of RTKs [13-18]. Herein, we present a general overview of the diverse mechanisms contributing to the crosstalk between GPCRs and RTKs.

\section{Ligand-Dependent Triple-Membrane-Passing-Signal (TMPS) Mechanisms:}

\section{Role of Membrane-Bound Matrix Metalloproteases (MMPs) and the A Disintegrin and Metalloproteases (ADAMs)}

Matrix metalloproteases belong to the calcium-dependent endopeptidases family. The members of this family are structurally and functionally related and are secreted in an inactive form (pro-MMPs), which requires an activation step before they are able to cleave extracellular matrix (ECM) components. Other members of metalloproteases include ADAMs and ADAMs with Thrombospondin motifs (ADAMTs) enzymes. The cleavage of ECM by MMPs triggers cell migration [19] and the liberation of proforms of cytokines, growth factors and chemokines anchored to the plasma membrane [20,21]. 
Several MMPs are involved in GPCR-mediated transactivation of different RTKs such as epidermal growth factor receptor (EGFR) [22-25], vascular endothelial growth factor receptor (VEGFR) [26-28] and platelet-derived growth factor receptor (PDGFR) [29,30], and this process is linked to MMP-mediated shedding of ligands, which in turn activate growth factor receptors (Figure 1). Several members of the MMP family are involved in the ectodomain shedding of EGFR ligands and, in turn, in EGFR transactivation. MMP-2 and MMP-9 represent important regulators of EGFR ligand release in isolated preovulatory ovarian follicles stimulated with the pituitary peptide - hormon luteinizant ( $\mathrm{LH}$ ) [31] and in gonadotropin-releasing hormone-stimulated (GnRH) gonadotropic cells [32], whereas MMP-7 mediates heparin-binding EGF-like growth factor (HB-EGF) shedding and EGFR transactivation in phenylephrine-stimulated arteries [33]. In some cases MMPs activation is downstream to EGFR transactivation. In fact, histamine stimulation of the histamine 2 (H2) receptor, a member of the GPCR family, evokes MMP-1 secretion that is dependent on the EGFR transactivation, as demonstrated by the inhibitor effect of the EGFR tyrosine kinase inhibitor AG1478 on the histamine-mediated MMP-1 secretion [34]. Moreover, in cultured chondrocytes thrombin increases the expression of MMP-13 by interacting with members of protease activated receptors (PARs) [35]. Another molecular signaling platform contemplates a neurominidase-1 (Neu-1)-MMP-9 crosstalk in alliance with the GPCR neuromedin B in activating EGFR. Central to this process is that Neu-1 and MMP-9 form a complex tethered at the ectodomain of EGFRs on the cell surface and that EGF binding induces a conformational change of EGFR to trigger MMP-9 activation and, in turn, Neu-1 stimulation. $\alpha-2,3$-sialyl residues associated to $\beta$-galactosides, elsewhere from the EGF binding site, are hydrolysed by activated Neu1 [24]. In other examples the members of the MMP family involved in EGFR transactivation are not yet characterized. In fact, in human colonic myofibroblasts (18Co) cells chronic exposure to tumor necrosis factor (TNF- $\alpha$ ) drives to up-regulation of EGFR in association with sustained lysophosphatidic acid (LPA)-mediated EGFR phosphorylation at Y1068, which is prevented by MMP inhibitors [36]. In cell culture models LPA also enhances corneal epithelial wound healing, which is prevented by tyrphostin, by MMPs inhibitors or by an HB-EGF antagonist. These inhibitors retard LPA-induced activation of EGFR and its downstream effectors extracellular-signal-regulated-kinases (ERKs) and Akt. The level of LPA-dependent EGFR phosphorylation is similar to that induced by wounding. However, LPA appears to prolong wound-induced EGFR signaling through its ability to induce autocrine HB-EGF signaling [37].

These data suggest the possible participation of MMPs in GPCR-induced EGFR transactivation in some settings and underline the ability of some MMPs to cleave proHB-EGF to produce mature HB-EGF (Table 1).

Agonist-bound GPCRs also activate members of the ADAM family, which in turn may transactivate different RTKs in several cell lines. ADAMs sheddase are a family of metalloproteases able to generate many diverse bioactive cytokines and growth factors by ectodomain shedding and to regulate many important cellular processes as growth, adhesion and motility of cells. Ectodomain cleavage is made specific by a number of intracellular signals, such as calcium influx, activation of GPCRs (Figure 1), and the release of diacylglycerol $[38,39]$. In the human genome 12 functional ADAMs have been identified and only ADAM10, ADAM12 and ADAM17 are the sheddases of the EGFR ligands in response to various shedding stimulants, such as GPCR agonists, growth factors, phorbol esters and cytokines [40,41]. The specificity and regulation of ADAMs involved in RTK transactivation is complex and depends on GPCR agonists and cell types under investigation. In cardiomiocytes Angiotensin II (Ang II) binds to Ang II type 1 (AT1) receptor, belonging to the GPCR family, and induces EGFR transactivation through HB-EGF shedding 
mediated by ADAM17 [42]. In kidney cancer cell lines, LPA-induced HB-EGF shedding and subsequent EGFR transactivation is mediated by ADAM10 in ACHN cells, whereas ADAM17 is responsible for these events in human renal carcinoma cells (CaKi2) and Human kidney carcinoma cell line (A498) [43]. In human tongue epithelial carcinoma cells (SCC-9) squamous carcinoma cell line ADAM17 mediates also amphiregulin shedding and EGFR transactivation by LPA [44] and in human urinary bludder epithelial cells (TccSup) ADAM15 mediates LPA-induced shedding of TGF- $\beta$ [43]. In general ADAMs are required in EGFR transactivation by GPCRs and only few exceptions demonstrate the involvement of MMPs in this process.

Figure 1. Ligand-dependent tyrosine kinase receptor (RTK) transactivation. Stimulation of G-protein-coupled receptors (GPCRs) with a selective agonist (A) triggers different intracellular signaling mediators via activation of $G \alpha$ and/or $G \beta \gamma$ subunits. Metalloprotease-mediated proteolytic cleavage of a Pro-Ligand generates a Ligand which binds and transactivates RTK.

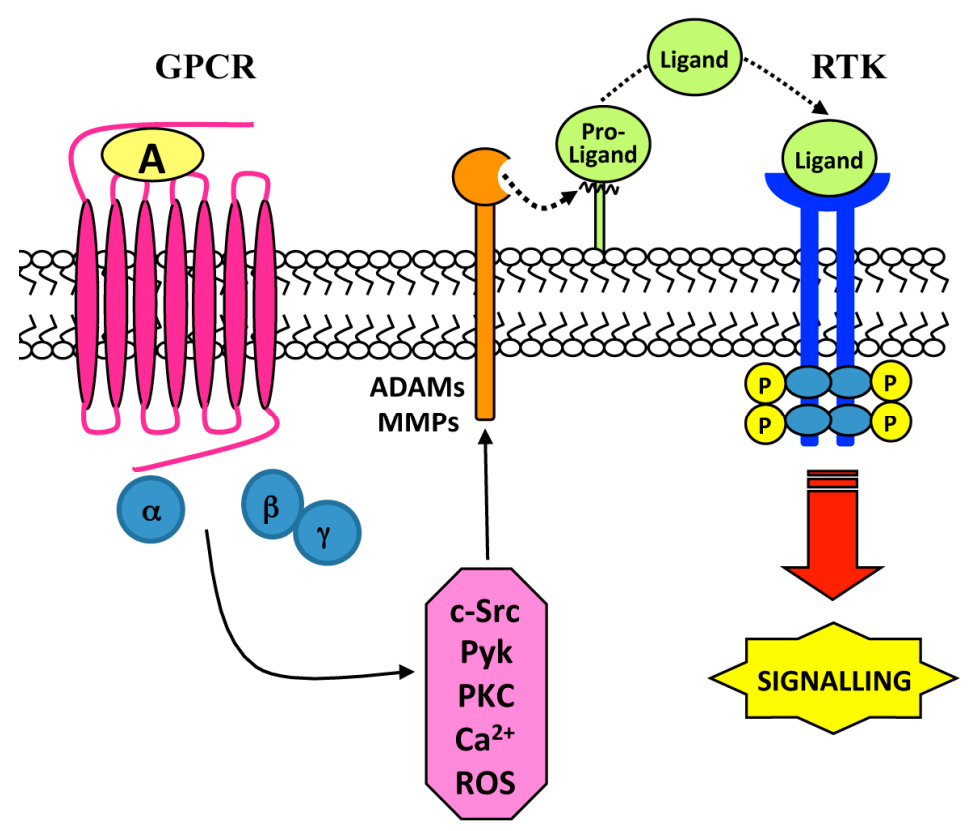

GPCR stimulation results in ADAM-dependent shedding also of other proteins, such as interleukin-6 (IL-6) receptor shedding in neutrophils [45], TNF- $\alpha$ shedding through ADAM17 in neuronal cells [46], ADAM10/17-dependent shedding of amyloid precursor protein in astrocytoma cells [47]. ADAM10/17 stimulation generates also the chemokine family of the GPCR ligands (CX3CL1 (Chemokine (C-X3-C motif) ligand 1), CXCL-16 (Chemokine (C-X-C motif) ligand 16)) by shedding in several cellular systems [41]. The chemokine interleukin-8 (IL-8) binds to interleukin 8 receptor alpha (IL-8RA) (Chemokine receptor type 1, CXCR1) and Interleukin 8 receptor beta (IL-8RB) (Chemokine receptor type 2, CXCR2), which are members of the GPCR family. In colon cancer cells, stimulation of these receptors induces shedding of EGF ligands via activation of ADAMs with subsequent EGFR tyrosine phosphorylation [48]. In general, ADAM10 and -17 cleave most disease-relevant substrates and their general inhibitors do not have a significant clinical application. Since it is not possible to target and to cleave specific substrates, it is necessary to identify signaling intermediates that determine substrate specificity of cleavage [40]. 
Table 1. RTKs transactivation: role of metalloproteases.

\begin{tabular}{|c|c|c|c|c|c|c|}
\hline Cell Lines & Stimulus & GPRC & Metalloproteases & RTK & Biological Responses & Ref. \\
\hline Pancreatic cancer cells & EGF & Neuromedin B & MMP-9 & EGFR & EGFR transactivation, cancer growth and metastatic spread & [24] \\
\hline $\begin{array}{l}\text { Isolated preovulatory ovarian follicles, } \\
\qquad \text { Y1 adrenal cells }\end{array}$ & LH & LHRH & MMP-2-9 & EGFR & EGFR transactivation, steroidogenesis & [31] \\
\hline Gonadrotropic cells & GnRH & GnRHR & MMP-2-9 & EGFR & EGFR transactivation, Src, Ras and ERKs activation & [32] \\
\hline Mesenteric arteries & Phenylephrine & $\alpha 1 \mathrm{~B}$-Adrenoreceptor & MMP-7 & EGFR & EGFR transactivation, vasoconstriction, growth & [33] \\
\hline Gastrics epithelial cells & Histamine & $\mathrm{H} 2 \mathrm{R}$ & MMP-1 & EGFR & EGFR transactivation, MAPK activation & [34] \\
\hline Chondrocytes & Thrombin & PARs & MMP-13 & EGFR & EGFR transactivation, PI3K/Akt pathway and AP1 activation & [35] \\
\hline $18 \mathrm{Co}$ & LPA, TNF- $\alpha$ & LPA1 & MMP & EGFR & EGFR transactivation, MAPK phosphorylation, COX2 expression & [36] \\
\hline Corneal epithelial cells & LPA & LPA1 & MMP & EGFR & $\begin{array}{c}\text { EGFR transactivation, ERK-Akt activation, } \\
\text { wound healing, proliferation }\end{array}$ & [37] \\
\hline Cardiomyocytes & Ang II & AT1 & ADAM17 & EGFR & EGFR transactivation, MAPK activation, angiogenesis & [42] \\
\hline $\begin{array}{c}\text { Kidney cancer cells, Bludder } \\
\text { carcinoma cells, Caki2, A498, TccSup }\end{array}$ & LPA & LPA1 & ADAM10-15-17 & EGFR & $\begin{array}{l}\text { EGFR transactivation, MAPK activation, } \\
\text { tumor cell migration and invasion, TGF- } \beta \text { shedding }\end{array}$ & [43] \\
\hline SCC-9 & LPA, Carbachol & LPA, AChR & ADAM17 & EGFR & $\begin{array}{l}\text { EGFR transactivation, amphiregulin shedding, ERKs activation, } \\
\text { PI3K/Akt activation, cell proliferation, migration }\end{array}$ & [44] \\
\hline Neuroectodermal cells & Serotonin, Nor-epinephrine & $\begin{array}{l}\text { 5-HT2B, } \\
\alpha 1 \mathrm{D}-\text { Adrenoreceptor }\end{array}$ & ADAM17 & EGFR & EGFR transactivation, NADPH oxidase activation & [46] \\
\hline Astrocytoma cells & UTP & $\mathrm{P} 2 \mathrm{Y} 2 \mathrm{R}$ & ADAM10-17 & EGFR & EGFR transactivation, amyloid precursor shedding & [47] \\
\hline Colon cancer cells & Interleukin-8 & CXCR1, CXCR2 & ADAMs & EGFR & EGFR transactivation, MAPK activation, cell growth & [48] \\
\hline $\left.\mathrm{CHO}, \mathrm{EC}-4^{\left(\mathrm{TACE}^{+/+}\right)} \mathrm{EC}-2^{(\mathrm{TACE}} \Delta \mathrm{Zn} / \Delta \mathrm{Zn}\right)$ & ATP & P2Y2R & ADAM17 & EGFR & EGFR transactivation & [49] \\
\hline
\end{tabular}

18Co, Human colonic myofibroblasts; 5-HT2B, Serotonin receptor 2B; A498, Human kidney carcinoma cell line; AChR, Acetylcholine receptor; Ang II, Angiotensin II; AT1, Angiotensin II receptor type 1; ATP, Adenosine triphosphate; Caki2, Human renal carcinoma cells; CHO, Chinese hamster ovary cell line; CXCL12, Chemokine 12; CXCR1, Chemokine receptor type 1; CXCR2, Chemokine receptor type 2; CXCR4, Chemokine receptor type 4; EC-4 (TACE +/+) and EC-2 (TACE $\triangle \mathrm{Zn} / \triangle Z \mathrm{Zn})$, Mice fibroblasts cell lines; EGF, Epidermal growth factor; EGFR, Epidermal growth factor receptor; GnRH, Gonadotropin-releasing hormone; GnRHR, Gonadotropin-releasing hormone receptor; H2R, Histamine receptor; LH, Hormon luteinizant; LHRH, Luteinizing-hormone receptor; LPA, Lysophosphatidic acid; LPA1, Lysophosphatidic acid receptor type 1; N15C6, Human prostate epithelial cells; P2Y2R, Nucleotide receptor; PARs, Protease activated receptors; SCC-9, Human tongue epithelial carcinoma cells; TccSup, Human urinary bludder epithelial cells; TNF- $\alpha$, Tumor necrosis factor; UTP, Uridine triphosphate. 
Both MMPs and ADAMs have been implicated in ectodomain shedding of HB-EGF induced by ROS [50], which may oxidize the electrophilic thiol groups in the pro-domain of ADAMs and disrupt the cysteine-zinc bond, leading to the active form of the enzyme [9]. In fact, in tumor cells oxidative stress induces ADAM-9, -10, and -17 activity which results in cell-surface cleavage of pro-HB-EGF and subsequent EGFR transactivation [51] and adenosine triphosphate (ATP)-dependent activation of the purinergic receptor of the P2Y family of GPCRs stimulates TGF $\alpha$ proteolysis with concomitant EGFR activation, in both murine fibroblasts and Chinese hamster ovary (CHO) cells [49]. This process requires ADAM17 activity and ROS production by mitochondrial oxidative complex [49] (Table 1).

\section{Ligand-Independent Mechanisms: Role of Reactive Oxygen Species (ROS)}

Phosphorylation of receptor and non-receptor tyrosine kinases is a critical step in signal transduction that drives to specific cellular functions. ROS can activate many protein tyrosine kinases through different mechanisms [52]. In fact, ROS (1) may directly activate kinases by altering protein-protein interactions; (2) may directly inactivate by oxidation the cysteine residue in the catalytic site of protein tyrosine phosphatases, which in turn results in tyrosine kinases activation; (3) may stimulate proteolysis of regulatory proteins inhibiting tyrosine kinase activity [53].

ROS are produced by a variety of extracellular stimuli such as growth factors, GPCR agonists, cytokines, ultraviolet radiation, increased osmolarity, and other cellular stresses [54]. Sources of their production include mitochondria [49], xanthine oxidase [55] and NADPH oxidase (Nox) family (Figure 2) [56], which generate superoxide anion $\left(\mathrm{O}_{2} \cdot\right)$, hydrogen peroxide $\left(\mathrm{H}_{2} \mathrm{O}_{2}\right)$, and hydroxyl radical $(\mathrm{OH} \cdot)$ involved in intracellular redox signaling. The pathophysiological effects of these molecules depend on their concentration, subcellular localization and the endogenous antioxidant status [57]. Plasma membrane-associated Nox family members are the only enzymes that generate ROS as their primary purpose in a highly regulated and spatial restricted manner, apparently suited for cell signaling $[58,59]$ and are considered the main source of ROS acutely produced upon growth factor or cytokine stimulation [60,61]. Seven isoforms of the catalytic subunit (Nox1-5, Duox1 and 2) of NADPH oxidase, expressed in several cell types, have been identified. 
Figure 2. NADPH oxidase-dependent RTK transactivation. Agonist (A) stimulation of GPCRs induces $\mathrm{p} 47^{\text {phox }}$ phosphorylation and NADPH oxidase activation, which generates reactive oxygen species (ROS) by $\mathrm{O}_{2}$ using NADPH as electron donor. ROS inactivate phosphotyrosine-phosphatases (PTPs) by oxidation of a cysteine in the catalytic domain, unbalancing intracellular phosphorylation equilibrium. The enhanced activity of phosphotyrosine-kinases (PTKs) mediates the trans-phosphorylation of tyrosines in the cytosolic region of RTK which, in turn, provide docking sites for assembly and activation of signaling complexes.

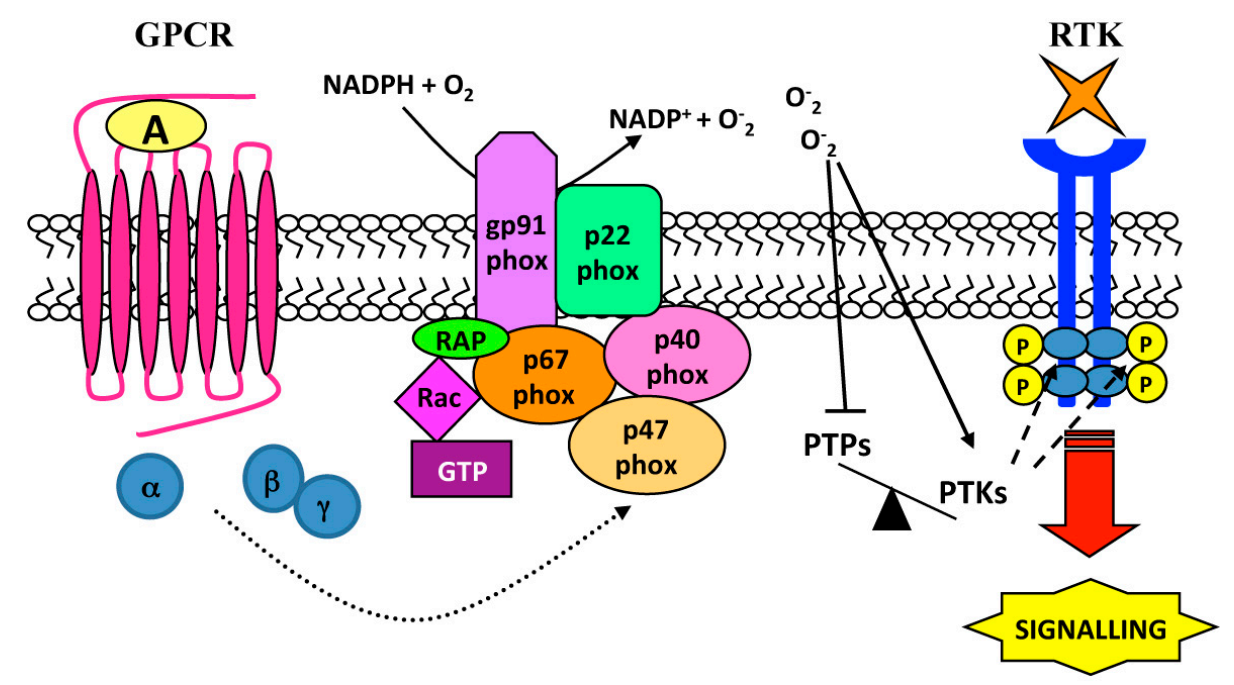

In vascular smooth muscle cells (VSMCs) binding of Ang II to AT1 receptor triggers NADPH oxidase-dependent superoxide generation, which is responsible for EGFR phosphorylation at Y1068 [62]. In the same cells metalloprotease-dependent shedding of HB-EGF is required for $\mathrm{H}_{2} \mathrm{O}_{2}$-induced EGFR transactivation [63], and PAR1/PAR3 stimulation by thrombin induces Nox1-dependent generation of ROS, which results in EGFR transactivation via metalloprotease shedding of EGF-like ligands [64,65].

ROS generated by GPCR stimulation can result in transactivation of more RTKs, suggesting that instead of a single GPCR to single RTK cross-talk, a less selective more global RTK response to GPCR activation can occur. For instance, serotonin (5-HT) binds and activates six GPCRs and transactivates PDGFR- $\beta$ receptor, as well as the tyrosine kinase receptor TrkB, through a NADPH oxidase-dependent mechanism, both in neuronal cultures and SH-SY5Y cells [66]. NADPH oxidase inhibitors prevent 5-HT-induced PDGFR- $\beta$ phosphorylation, which is also dependent on PKC activity likely acting upstream of NADPH oxidase [66].

The mechanism of ROS-induced EGFR transactivation may involve non-receptor tyrosine kinases [13,67]. In VSMCs, Ang II induces ROS production via NADPH oxidase activation and EGFR transactivation [68]. In these cells c-Src acts as upstream regulator of EGFR transactivation and is also required for ROS generation [68]. Moreover, in human lung cancer cells Formyl-peptide receptor, a member of the GPCR family, stimulated with WKYMVm induces EGFR transactivation, which depends on c-Src activity. Apocynin, a NADPH oxidase inhibitor, or a siRNA against the catalytic subunit p22 ${ }^{\text {phox }}$ of NADPH oxidase prevents EGFR transactivation and c-Src kinase activity [67]. In endothelial cells exposed to $\mathrm{H}_{2} \mathrm{O}_{2}$ the selective c-Src inhibitor PP2 prevents EGFR transactivation [69]. 
Several GPCR agonists activate Gq proteins family. The resulting GTP-Gaq complex activates PLC $\beta$ via interaction with the carboxy-terminal region of the enzyme [70]. The $\beta \gamma$ subunits of $G$ proteins can also stimulate PLC $\beta$, as suggested by the observation that mitogenic GPCR ligands trigger the $\beta \gamma$-mediated stimulation of PLC $\beta 2$ and PLC $\beta 3$ [70]. Activate PLC isoforms catalyze the hydrolysis of phosphatydyl-inositol 4,5-bisphosphate (PIP2) to produce inositol 1,4,5-triphosphate (IP3) and diacylglycerol (DAG). IP3 triggers $\mathrm{Ca}^{2+}$ mobilization from endoplasmic reticulum stores leading to an increase of intracellular concentration of $\mathrm{Ca}^{2+}$ [71]. The most prominent intracellular targets of DAG are the classical and novel isoforms of PKC. In VSMCs ROS-induced EGFR transactivation may involve an increase of intracellular $\mathrm{Ca}^{2+}$ concentration, which is required for Ang II-dependent EGFR transactivation. Ang II induces ROS generation via NADPH oxidase activation [72] and since $\mathrm{H}_{2} \mathrm{O}_{2}$ has no effects on intracellular $\mathrm{Ca}^{2+}$, this ion may mediate ROS production which in turn triggers EGFR transactivation [73]. On the other hand, in mouse embryonic cells $\mathrm{H}_{2} \mathrm{O}_{2}$ increases intracellular $\mathrm{Ca}^{2+}$ concentration and the phosphorylation of PKC, ERKs, p38Mitogen-activated protein kinase (p38MAPK) and c-Jun $N$-terminal kinase (JNK), as well as EGFR transactivation stimulating, in turn, cell proliferation [74]. In WKYMVm-stimulated human fibroblasts, $\mathrm{Ca}^{2+}$-dependent PKC $\alpha$ isoform is required for the phosphorylation of the regulatory subunit $\mathrm{p} 47^{\text {phox }}$ of NADPH oxidase [75].

Similar to EGFR, PDGFR can be activated not only by its cognate ligands but also by other stimuli in a ligand-independent manner. The transactivation of the PDGFR $\beta$ by GPCRs appears to involve ROS in VSMCs. In fact, in these cells hydrogen peroxide induces a ligand-independent tyrosine phosphorylation of PDGFR at Tyr1021, a PLC $\gamma$ binding site, as well as the association of PKC $\delta$ with PDGFR $\beta$ and c-Src [76].

In human hepatocellular and pancreatic carcinoma cells the c-Met receptor becomes tyrosine phosphorylated in response to several GPCRs agonists, such as lysophosphatidic acid (LPA), bradichinin, thrombin, charbachol and endothelin. c-Met transactivation is prevented by reducing agents or treatment of cells with diphenylene iodonium [77], suggesting that it requires the acute production of ROS by membrane-bound NADPH oxidase. Phosphorylated tyrosines of c-Met provide docking sites for the triggering of intracellular signaling pathways [78]. In fact, WKYMVm, a Formyl-peptide receptor 2 agonist, induces the transactivation of c-Met in a human prostate epithelial cell line. The WKYMVm-induced phosphorylation of Y1313, Y1349 and Y1356 residues of c-Met in the intra-cytoplasmic domain elicits the activation of signal transducer and activator of transcription 3 (STAT3), PLC- $\gamma 1 / \mathrm{PKC} \alpha$ and phosphatidylinositol-3kinase (PI3K)/Akt pathways, similarly to the molecular responses elicited by c-Met/HGF binding [79]. The critical role of NADPH oxidase-dependent ROS production in this crosstalk mechanism is supported by the finding that blockade of NADPH oxidase function prevents c-Met trans-phosphorylation and downstream signaling cascades [79]. FPR and the two RTKs, nerve growth factor (NGF) receptor neurotrophic tyrosine kinase receptor type 1 (TrkA) and EGFR, crosstalk each other to modulate pro-inflammatory mediators, to produce ROS, to activate MMP-9 and to up-regulate CD11b membrane integrin. In response to $N$-formyl-methionylleucyl-phenilalanine ( $N$-fMLP), an FPR agonist, TrkA phosphorylation is prevented by EGFR inhibitors while EGFR phosphorylation is prevented by a TrkA inhibitor. Receptor crosstalk is Src- and ERK-dependent [80] (Table 2). 
Table 2. RTKs transactivation: role of ROS.

\begin{tabular}{|c|c|c|c|c|c|c|}
\hline Cell Lines & Stimulus & GPCR & $\begin{array}{l}\text { Source } \\
\text { of ROS }\end{array}$ & RTKs & Biological Responses & Ref. \\
\hline VSMCs & Ang II & AT1 & $\begin{array}{l}\text { NADPH } \\
\text { oxidase }\end{array}$ & EGFR & $\begin{array}{l}\text { EGFR transactivation, ERKs } \\
\text { activation, growth }\end{array}$ & {$[62]$} \\
\hline SMC & Thrombin & PARs & NOX1 & EGFR & $\begin{array}{l}\text { EGFR transactivation, PI3K-Akt and } \\
\text { ATF-1 activation, migration and } \\
\text { proliferation, } N \text {-cadherin shedding } \\
\text { mediated by MMP- } 9 \text {, ERKs activation }\end{array}$ & {$[64,65]$} \\
\hline SH-SY5Y & 5-HT & 5-HTR & $\begin{array}{l}\text { NADPH } \\
\text { oxidase }\end{array}$ & $\begin{array}{l}\text { PDGFR- } \beta, \\
\text { TrkB }\end{array}$ & $\begin{array}{l}\text { PDGFR- } \beta \text { transactivation, TrkB } \\
\text { transactivation }\end{array}$ & [66] \\
\hline Calu-6 & WKYMVm & FPR2 & $\begin{array}{l}\text { NADPH } \\
\text { oxidase }\end{array}$ & EGFR & $\begin{array}{l}\text { EGFR transactivation, cell growth, } \\
\text { STAT3 activation, } \\
\text { PI3K/Akt activation }\end{array}$ & [67] \\
\hline VSMCs & Ang II & AT1 & $\begin{array}{l}\text { NADPH } \\
\text { oxidase }\end{array}$ & EGFR & $\begin{array}{l}\text { EGFR transactivation, increase } \\
\text { of intracellular } \mathrm{Ca}^{2+} \text { concentration, } \\
\text { MAPK activation }\end{array}$ & [72] \\
\hline $\begin{array}{l}\text { DAN-G, } \\
\text { HepG2, } \\
\text { HuH7 }\end{array}$ & $\begin{array}{l}\text { LPA, } \\
\text { Bradykinin, } \\
\text { Thrombin, } \\
\text { Carbachol, } \\
\text { Endothelin }\end{array}$ & $\begin{array}{c}\text { LPA1, } \\
\text { BDKRB1-2, } \\
\text { PARs, } \\
\text { mAChRs, } \\
\text { EDNRs }\end{array}$ & $\begin{array}{l}\text { NADPH } \\
\text { oxidase }\end{array}$ & $\begin{array}{l}\text { EGFR, } \\
\text { c-Met }\end{array}$ & $\begin{array}{c}\text { EGFR and c-Met transactivation, } \\
\beta \text {-catenin nuclear traslocation, } \\
\text { cell motility }\end{array}$ & [77] \\
\hline PNT1A & WKYMVm & FPR2 & $\begin{array}{l}\text { NADPH } \\
\text { oxidase }\end{array}$ & c-Met & $\begin{array}{c}\text { c-Met transactivation, } \\
\text { cell proliferation, STAT3 activation, } \\
\text { PI3K/Akt activation, } \\
\text { PLC } \gamma / \text { PKC } \alpha \text { activation }\end{array}$ & [79] \\
\hline Monocytes & $N$-fMLP & FPR & $\begin{array}{c}\text { NADPH } \\
\text { oxidase }\end{array}$ & $\begin{array}{c}\text { EGFR, } \\
\text { TrkA }\end{array}$ & $\begin{array}{l}\text { EGFR and TrkA transactivation, } \\
\text { CD11b membrane up-regulation }\end{array}$ & [80] \\
\hline
\end{tabular}

5-HT, Serotonin; 5-HTR, Serotonin receptor; Ang II, Angiotensin II; AT1, Angiotensin II receptor type 1; BDKRB1-2, Bradykinin receptor B1-2; c-Met, Hepatocyte growth factor receptor; Calu-6, Human lung cancer cells; DAN-G, Human pancreatic carcinoma cells; EDNRs, Endothelin receptors; EGFR, Epidermal growth factor receptor; FPR, $N$-formyl peptide receptor; FPR2, $N$-formyl peptide receptor 2; HepG2, Human hepatocyte cell line; HuH7, Human hepatocarcinoma cell line; LPA, Lysophosphatidic acid; LPA1, Lysophosphatidic acid receptor type 1; mAChRs, Muscarinic acetylcholine receptors; PARs, Protease activated receptors; PDGFR- $\beta$, Platelet-derived growth factor receptor; PNT1A, Human prostatic cell line; SH-SY5Y, Human neuronal cells; SMC, Human smooth muscle cells; TrkA, Neurotrophic tyrosine kinase receptor type 1; TrkB, Neurotrophic tyrosine kinase receptor type 2; VSMCs, Human vascular smooth muscle cells.

\section{Ligand-Independent Mechanisms: Role of Intracellular Tyrosine Kinases}

The absence of detectable amounts of EGF-like ligands after GPCR stimulation suggests that GPCR-induced EGFR transactivation can be also triggered by intracellular signaling pathways, which require the presence of $\mathrm{Ca}^{2+}$ ions as well as $\mathrm{PKC}$ and intracellular tyrosine kinases activation [9].

Src family tyrosine kinases are an integral component of the signal transduction apparatus employed by RTKs, playing a key role in cellular growth and malignant transformation. Several 
molecular mechanisms allow GPCRs to activate Src family kinases, and conversely Src activity plays a central role in controlling GPCR responses. In many cases Src family kinases are associated with GPCRs through direct interaction with cytoplasmic receptor domains, which contain consensus SH3 domain-binding motifs or proline-rich motifs within their third intracellular loops or $C$-terminal tails, or by binding to GPCR-associated proteins, such as heterotrimeric G-protein subunits or $\beta$-arrestins. Src family kinases are also activated by GPCRs [81].

c-Src is regulated by G $\beta \gamma$ subunits and can interact with $\beta$-arrestin, which binds a number of signaling proteins. In some cell types the formation of $\beta$-arrestin-Src complex can requires GPCR phosphorylation. In fact, in human epidermoid carcinoma cells isoproterenol triggers tyrosine phosphorylation of $\beta 2$-adrenergic receptor ( $\beta 2 \mathrm{AR}$ ) playing a role in $\beta 2 \mathrm{AR}-\mathrm{Src}$ interaction [82]. In PC3 cells binding of neurotensin to Neurotensin receptors (NTRs), which are members of GPCR family, induces c-Src-dependent EGFR phosphorylation at Y845 [83], and several GPCR agonists induce rapid and transient activation of Src-family members in a variety of cell types (Figure 3) [84]. Stimulation of $\alpha 2 \mathrm{~A}$-adrenergic receptor (AR) results in EGFR transactivation and ERKs activation which requires c-Src activity and, in turn, the induction of HB-EGF shedding mediated by metalloproteases [85]. Alternatively, in response to GPCR-induced ROS generation, Src-family members directly phosphorylate EGFR [85].

In C9 cells stimulation of AT1 with Ang II results in the association of Pyk2 with Src and EGFR, as well as in ERKs activation. Src, Pyk2 and Ang II-induced ERKs phosphorylation mediated EGFR transactivation actin upstream to EGFR [86]. Also stimulation of the V2 vasopressin receptor (V2R) leads to the ERKs activation, through a c-Src-dependent, metalloprotease-mediated shedding of a factor activating Insulin Growth Factor Receptor (IGFR), which requires the presence of $\beta$-arrestins [87]. c-Src acts upstream of the metalloprotease activation and is required for the release of the IGFR-activating factor, whereas $\beta$-arrestins act downstream of the IGFR transactivation. The engagement of $\beta$-arrestins by IGFR, but not by V2R, is necessary to promote the vasopressin-stimulated ERKs activation. This role of $\beta$-arrestins is not limited to the V2R but also to other unrelated GPCRs, indicating that it may be a general mechanism shared among GPCRs [87].

Figure 3. Tyrosine kinases-dependent RTK transactivation. RTK transactivation may be mediated by non-receptor protein tyrosine kinases. GPCR-activated members of c-Src family induce a ligand-independent transactivation of a RTK via trans-phosphorylation of cytosolic tyrosines, which provide docking sites for triggering intracellular signaling cascades.

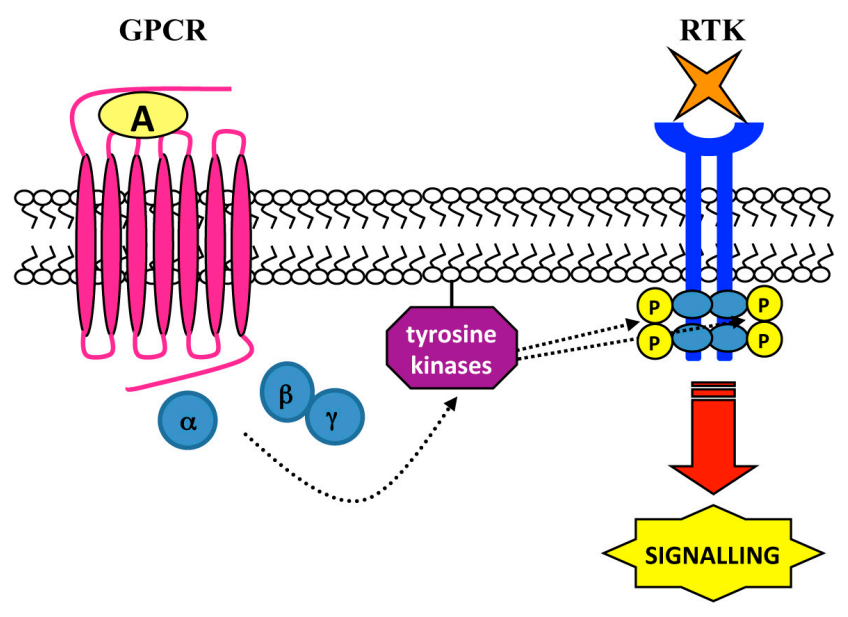


Formyl-peptide receptors 1, 2 and 3 (FPR1, 2 and 3) form a subgroup of receptors linked to inhibitory G-proteins [88]. Their activation by specific ligands triggers distinct signaling cascades in several cell types $[89,90]$. Stimulation of CaLu6 cells with the FPR2 agonist WKYMVm induces EGFR transactivation, p47 phox phosphorylation, NADPH-oxidase-dependent superoxide generation and c-Src kinase activity. Phosphorylated tyrosine residues of EGFR recruit and trigger the STAT3 pathway. The role of c-Src and ROS in this crosstalk mechanism is corroborated by the observation that a c-Src inhibitor or the blockade of NADPH oxidase function hampers EGFR transactivation. Furthermore, the NADPH oxidase inhibitor apocynin or a siRNA against the catalytic subunit $\mathrm{p} 22^{\text {phox }}$, prevents WKYMVm-induced c-Src activation [67].

Fyn, a member of the Src family kinase, plays a key role in regulating signaling events between Adenosine receptor and Trk. Fyn and Trk are colocalized in a juxtanuclear membrane compartment and Fyn expression is sufficient to allow transactivation of Trk by adenosine. These observations indicate that Fyn is activated by Adenosine receptor stimulation and is responsible for transactivation of Trk receptors on intracellular membranes [91]. c-Src activity is also required in serotonin-induced PDGFR $\beta$ phosphorylation through 5-hydroxytryptamine 1A (5-HT1A) receptors in SH-SY5Y neuroblastoma cells and in primary cortical neurons. The receptor transactivation is pertussis toxin (PTX)-sensitive and Src-dependent and requires PLC activity, intracellular calcium signaling and NADPH oxidase activation [92].

In many cases RTKs and GPCRs form a complex on which signals can be integrated to produce more efficient stimulation of intracellular pathways. PDGF and sphingosine 1-phosphate (S1P) induce the recruitment of c-Src to the PDGFR $\beta$-sphingosine 1-phosphate receptor 1 (S1P1) complex. This drives to the tyrosine phosphorylation of Grb2-associated-binding protein 1 (Gab1), which depends on $\mathrm{G}$ protein and c-Src activation, as well as the accumulation of dynamin II at the membrane, which is required for endocytosis of the PDGFR $\beta$-GPCR complex [93]. In other observations, ROS and Src-family kinases seems to act downstream of PDGFR to enhance PDGF-mediated tyrosine phosphorylation of various signaling intermediates [94]. The formation of functional complexes between RTKs and GPCRs is observed in different cell types [95,96]. For instance, in airway smooth muscle cells PDGFR $\beta$ and S1P1 form an active complex. The respective ligands (PDGF or S1P) do not induce changes in the association of these receptors in the complex and S1P does not induce tyrosine phosphorylation of PDGFR $\beta$ [95]. However, over-expression of S1P1 enhances the PDGF-stimulated activation of the ERKs pathway. [10]. In COS-7 cells, $\beta 2$-adrenergic receptor ( $\beta 2 \mathrm{AR}$ ) stimulation induces EGFR dimerization, tyrosine autophosphorylation and EGFR internalization. Isoproterenol exposure promotes the formation of a multireceptor complex containing $\beta 2 \mathrm{AR}$ and the transactivated EGFR. Selective inhibitors of Src kinases prevent $\beta 2 \mathrm{AR}$-mediated EGFR phosphorylation, indicating that this kinase is required for EGFR transactivation [97]. Similarly, in gastric mucosal cells stimulated with isoproterenol, PP2 prevents EGFR transactivation and gastric mucin secretion [98]. Src family kinases are also required in the insulin-like growth factor (IGF)-mediated transactivation of active pituitary adenylate cyclase-activating peptide type 1 receptor (PAC1R), which is constitutively associated to the insulin-like growth factor 1 receptor (IGF-1R) and is involved in IGF-1-induced survival of neurons [99].

Other functional complexes between GPCRs and RTKs do not require the action of intracellular tyrosine kinases for the transactivation mechanism. This is the case of TrkA receptor/neurotrophic 
tyrosine kinase receptor type 1 (TrkA/NTRK1) association [100] and of S1P1/VEGFR2, which forms a complex associated to PKC and ERKs [101].

Much less is known regarding the ability of ROS and Src-family members to indirectly and chronically activate monomeric PDGFR $\alpha$. However, the possible involvement of metalloproteases in the PDGFR transactivation mechanism and, in turn, the applicability of the TMPS model is not clear. The ligand-dependent mechanism requires the existence of latent growth factors that could be activated by proteolytic cleavage. Although latent ligands of PDGFR (platelet-derived growth factor $\mathrm{C}$ and platelet-derived growth factor D) have been discovered, their possible partecipation in the PDGFR transactivation has not yet been investigated [102].

Activation of intracellular tyrosine kinases can require the presence of $\mathrm{Ca}^{2+}$ ions. In cardiomyocytes the Endothelin-1 (ET)-mediated activation of the tyrosine kinase Pyk2 is abrogated by chelating $\mathrm{Ca}^{2+}$ or by down-regulation of PKC, whereas ET-1-mediated transactivation of EGFR is solely dependent on PKC, suggesting the existence of two distinct tyrosine kinase pathways requiring Pyk2 or PKC activation downstream from GPCR [103] (Table 3).

Table 3. RTKs transactivation: role of tyrosine kinases.

\begin{tabular}{|c|c|c|c|c|c|c|}
\hline Cell Lines & Stimulus & GPCR & $\begin{array}{l}\text { Tyrosine } \\
\text { Kinases }\end{array}$ & RTK & Biological Responses & Ref. \\
\hline PC3 & Neurotensin & NTRs & c-Src & EGFR & $\begin{array}{l}\text { EGFR transactivation, cell } \\
\text { proliferation, } \\
\text { DNA synthesis, } \\
\text { STAT5-b activation }\end{array}$ & [83] \\
\hline COS-7 & $\begin{array}{l}\alpha 2-\mathrm{AR} \\
\text { agonists }\end{array}$ & $\alpha 2-\mathrm{AR}$ & c-Src & EGFR & $\begin{array}{l}\text { EGFR transactivation, } \\
\text { ERK activation }\end{array}$ & [85] \\
\hline C9 & Ang II & AT1 & c-Src/Pyk2 & EGFR & $\begin{array}{l}\text { EGFR transactivation, } \\
\text { ERKs phosphorilation }\end{array}$ & [86] \\
\hline HEK293 & AVP & V2R & c-Src & IGFR & $\begin{array}{l}\text { IGFR transactivation, } \\
\text { ERKs activation }\end{array}$ & [87] \\
\hline PC12-615 & $\begin{array}{l}\text { Adenosine, } \\
\text { GCS21680 }\end{array}$ & $\begin{array}{l}\text { Adenosine } \\
\text { receptor }\end{array}$ & Fyn & TrkA & TrkA transactivation. & [91] \\
\hline SH-SY5Y & 5-HT & 5-HT1A & $\mathrm{c}-\mathrm{Src}$ & PDGFR- $\beta$ & PDGFR- $\beta$ transactivation & [92] \\
\hline COS-7 & Isoproterenol & $\beta 2 \mathrm{AR}$ & c-Src & EGFR & $\begin{array}{l}\text { EGFR transactivation, } \\
\text { ERKs activation }\end{array}$ & [97] \\
\hline $\begin{array}{l}\text { Gastric mucosal } \\
\text { cells }\end{array}$ & Isoproterenol & $\beta 2-A R$ & $\mathrm{c}-\mathrm{Src}$ & EGFR & $\begin{array}{l}\text { EGFR transactivation and } \\
\text { regulation of gastric mucin } \\
\text { secretion }\end{array}$ & [98] \\
\hline Cardiomyocytes & Endothelin-1 & ET-1 & Pyk2 & EGFR & $\begin{array}{l}\text { EGFR transactivation, } \\
\text { MAPK activation }\end{array}$ & [103] \\
\hline
\end{tabular}

5-HT, Serotonin; 5-HT1A, Serotonin receptor; Ang II, Angiotensin II; AT1, Angiotensin II receptor type 1; AVP, Vasopressin; C9, Rat hepatic cells; COS-7, Fibroblast-like cell line; EGFR, Epidermal growth factor receptor; ET-1, Endothelin receptor; HEK293, Human embryonic kidney 293 cells; IGFR, Insulin-like growth factor 1 receptor; NTSR, Neurotensin receptor; PC12-615, Rat pheochromocytoma cell line; PC3, Human prostate carcinoma cells; PDGFR- $\beta$, Platelet-derived growth factor receptor; SH-SY5Y, Human neuronal cells; TrkA, Neutrophic tyrosine kinase receptor type 1; V2R, Vasopressin receptor; VSMCs, Vascular smooth muscle cells; $\beta 2 \mathrm{AR}, \beta 2$-Adrenergic receptors. 


\section{Role of $G$ Proteins and $\beta$-Arrestins in Transactivation}

RTKs can use $G$ proteins to induce activation of signaling pathways and this mechanism is distinct from RTK transactivation, in which the $G$ protein functions upstream of the RTK to transmit signals to effectors. Further studies reveal that Gi is constitutively associated with IGF-1R and that stimulation of cells with insulin results in a reduction in the amount of G $\beta \gamma$ associated with IGF-1R [10]. On the other hand IGF-1 binds to the Gi coupled chemokine receptor type 4 (CXCR4) in the absence of Chemokine 12 (CXCL12), the natural ligand of CXCR4, to promote migration of breast cancer cells [104]. This mechanism involves the regulation of Gai and $\beta \gamma$ subunits by IGF-1 [104].

Other RTK-G protein partnerships include PDGFR $\beta$ signaling in HEK293 cells over-expressing PDGFR $\beta$, where PDGF stimulates the tyrosine phosphorylation of Gai [10]. The interaction between RTKs and $\mathrm{G}$ protein is not restricted to $\mathrm{Gi}$, thereby demonstrating wider significance of this type of regulation. In fact, EGF stimulates the tyrosine phosphorylation of Gas, which is more effective at stimulating adenylyl cyclase than its non-phosphorylated counterpart [10]. Moreover, G $\alpha 13$ is essential for EGFRand PDGFR-induced migration of fibroblasts and endothelial cells in response to EGF and PDGF, respectively [105]. This suggests that G $\alpha 13$ is a critical signal transducer for RTKs, as well as for GPCRs.

There is no evidence that RTKs can directly activate G-proteins in a manner similar to a GPCR. PTX prevents Gi-proteins functional coupling with the GPCR by reducing activation of Gi induced by GPCR agonists. RTKs might use activated Gi provided by a constitutively active GPCR in a platform complex with the RTK and in this model, PTX interrupts the signaling from the RTK-GPCR association by preventing activation of Gi-protein by the GPCR [10].

$\beta$-Arrestins participate in cellular responses to growth factors, denoting additional evidence for a role of GPCRs in regulating RTK signal transmission. They are implicated in GPCRs desensitization but are also clathrin adaptor proteins, which can function as regulators of GPCR-dependent signaling. $\beta$-Arrestins can associate with the PDGFR $\beta$, TrkA, IGF-1R and EGFR in either a ligand-dependent or -independent manner [106-108], thereby suggesting either a unique interaction between RTK and $\beta$-arrestin or a potential role for $\beta$-arrestin associated with a GPCR in a complex with RTK [10].

$\beta$-Arrestins are involved in the GPCR-mediated transactivation of several RTKs, such as EGFR. For instance, $\beta 1 \mathrm{AR}$ specific agonists trigger $\beta$-arrestin-dependent EGFR phosphorylation, which is independent by $\mathrm{G}$ protein activation and requires GRK5/6 activity [109]. $\beta 1 \mathrm{AR}$ and EGFR form a complex at the plasma membrane and their interaction depends on $\beta 1 \mathrm{AR}$ phosphorylation by GRK and on recruitment of $\beta$-arrestin, which is required to maintain prolonged $\beta 1$ AR-EGFR interaction and to retain ERKs activation in the cytosol [18]. A genetic variant of $\alpha 1 \mathrm{AR}$ triggers a $\beta$-arrestin1/ c-Src/MMP/EGFR/ERK-dependent hyperproliferation of cardiomyoblasts, which is constitutive, and $\mathrm{Gq}$ independent, as well as a Gq/EGFR/STAT-dependent hypertrophy, which is induced by $\alpha 1 \mathrm{AR}$ agonists. These two distinct EGFR transactivation-dependent cascades induce the transition of cardiomyoblasts to fibroblast-like cells [23]. Urotensin II stimulation in an animal model of transverse aortic construction [14] and GPR54 stimulation by Kisspeptin-10 in human invasive breast carcinoma cells [110] represent other examples of $\beta$-arrestin-dependent EGFR transactivation.

$\beta$-Arrestins are also recruited to the IGF-1R, mediating intracellular signaling cascades. GRK plays a key role in this molecular mechanism, as demonstrated by the observation that silencing GRK expression abolished IGF-mediated ERKs phosphorylation and Akt activation [111]. Chronic insulin treatment induces 
to enhance $\beta$-arrestin1 degradation, which is associated with a decreased IGF-1, LPA and MAPK signaling, suggesting that insulin treatment can impair GPCR signaling [107]. A brief stimulation of $\mu$ opioid receptor (MOPR), a member of the GPCR family, with its specific agonist transactivates IGF-1R in SH-SY5Y cells. Small interfering siRNA for $\beta$-arrestin2 uncouple the cross-talk between the two receptors [112]. On the other hand, MMP-dependent IGF-1R transactivation induced by V2R stimulation requires c-Src activity, which acts upstream of the MMP activation, as well as $\beta$-arrestins, which act downstream of the IGF-1R transactivation [87]. Moreover, S1P induces recruitment of $\beta$-arrestin to S1P1/S1P3 receptor, c-Src activation and the binding of S1P1/S1P3 with Flk-1, increasing Flk-1 phosphorylation and, in turn, embryonic stem cell proliferation [113].

\section{GPCR-Mediated Transactivation of Serine/Threonine kinase (S/TK) Receptors and Toll-Like Receptors (TLRs)}

GPCR signaling involving receptor transactivation has been limited to RTKs but it can be extended to $\mathrm{S} / \mathrm{TK}$ receptors, such as TGF- $\beta$ receptor (T $\beta \mathrm{RI})$. Several GPCR agonists triggering T $\beta \mathrm{RI}$ transactivation have been identified. In VSMCs Endothelin-1 and thrombin bind to their specific GPCRs inducing a temporal increase of $C$-terminal phosphorylated Smad transcription factor (pSmad2) [114,115], which is the immediate downstream product of activation of the S/TK activity of T $\beta R$ I (Figure 4). The thrombin-mediated increase of pSmad 2 is insensitive to cycloheximide, suggesting a transactivation mechanism independent of gene activation and de novo protein synthesis [1]. In human epithelial cells, LPA induces $\alpha$ V $\beta 6$-integrin-mediated TGF- $\beta$ activation, via both Ras homolog member A (RhoA) and Ras homolog kinase (ROCK), which is elicited by Gaq associated to LPA2 receptor, a member of the GPCR family [116]. Similarly, in mice epithelial cells thrombin and other ligands of PAR1 activate TGF- $\beta$ in a $\alpha$ V $\beta 6$-integrin-dependent manner via RhoA and ROCK [117]. Stimulation with either LPA or thrombin induces a time-dependent generation of $\mathrm{pSmad} 2$, which is completely prevented by an $\alpha \mathrm{V} \beta 6$-integrin-specific neutralizing antibody [116,117]. In VSMCs, PAR1-mediated transactivation of T $\beta R I$ involves cytoskeletal rearrangement, ROCK and cell-surface Arg-Gly-Asp (RGD)-binding integrins. The resulting increase of pSmad2 phosphorylation plays a key role in proteoglycan synthesis [118]. In mouse VSMCs binding of Ang II to AT1 receptor induces T $\beta$ RI transactivation and small mother against decapentaplegic 2C ( $\mathrm{Smad} 2 \mathrm{C})$ phosphorylation, as well as the induction of collagen type I expression. The Ang II-iduced pSmad2 generation is abolished by $\alpha \mathrm{V} \beta 3$-integrin-specific neutralizing antibody, indicating that $\mathrm{S} / \mathrm{TK}$ receptors transactivation requires cell-type specific isoforms of integrins [119].

Another study provides evidence for S/TK Bone Morphogenetic Protein Receptor 1A (BMPR1A) transactivation by the GPCR agonist 5-HT. In bovine and human pulmonary artery smooth muscle cells, serotonin activates Smad 1/5/8 through the 5-HT 1B/1D receptor, a member of the GPCR family, and induces their translocation from cytoplasm to the nucleus. Smads phosphorylation depends on RhoA and ROCK signaling and is prevented by blockade of 5-HT 1B/1D receptor and by the expression of a negative dominant BMPR1A, suggesting that it requires the activation of both receptors [120].

There is also evidence for a crosstalk between GPCR and TLR signaling pathways. Mammalian TLRs recognize pathogen-associated molecular patterns and trigger intracellular signaling cascades in dendritic cells (DC). These include modified chemokine and cytokine production, altered chemokine receptor expression, and changes in signaling through GPCRs by altering the expression of regulator of $\mathrm{G}$ 
protein signaling (RGS) proteins [121]. In macrophage cells LPA, bombesin, Ang I and II, and bradikinin bind their respective GPCRs inducing a rapid Neul activity, which is prevented by PTX and MMP inhibitors. In particular, the bombesin-related Neuromedin B Receptor (NMBR) forms a complex tethered to the glycosylated TLR4, supporting the crosstalk between GPCR and TLR signaling pathways [122]. Thymoquinone also activates Neu1 and Neu4 sialidases on the cell-surface of DCs and macrophages via GPCR and Gai, and TLR 2/3/4 form a signaling platform with GPCR, Gai, MMP-9 and Neul (or Neu4) sialidase [123].

Figure 4. GPCR-mediated T $\beta$ RI transactivation. Stimulation of protease activated receptor 1 (PAR1) with thrombin induces the activation of Rho/ROCK which, in turn, triggers integrin-mediated TGF- $\beta$ activation. The activated ligand binds to T $\beta R I$ promoting the phosphorylation of Smad2 and the formation of pSmad activated complexes.

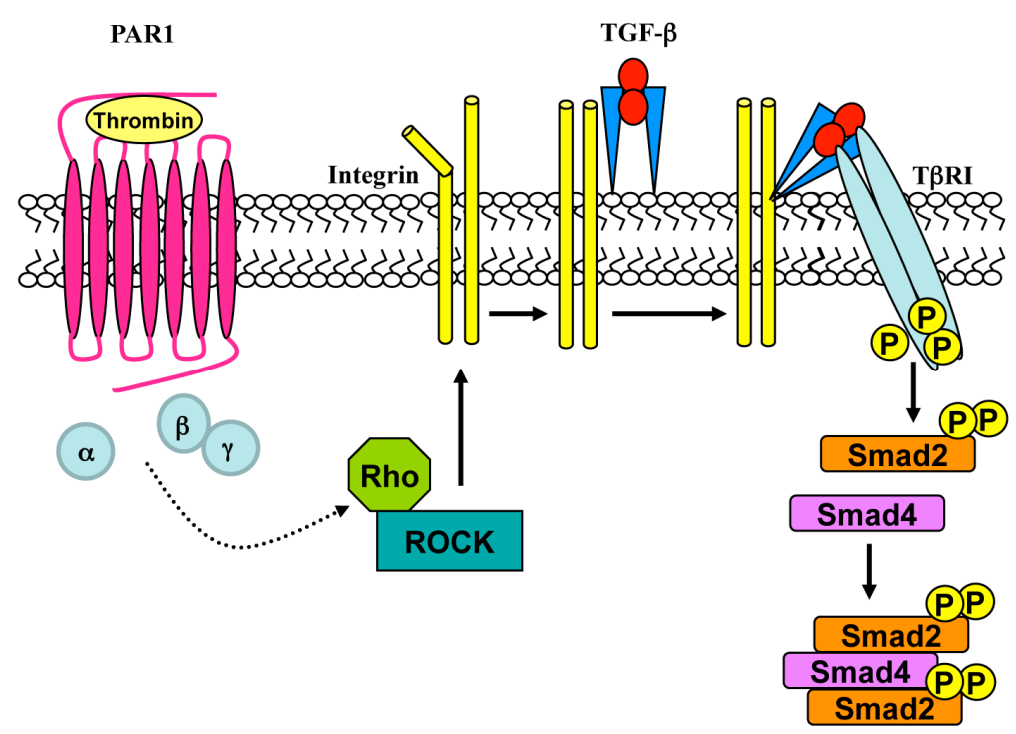

TLRs dimerization is essential for the ligand-induced activation and is a prerequisite to facilitate myeloid differentiation primary response 88 (Myd88)/TLR complex formation and subsequent intracellular signaling. In murine macrophages, Neu-1 sialidase and MMP-9 crosstalk, in alliance with NMBR tethered to TLR7 and 9, forms a GPCR signaling platform, which plays a key role in ligand activation of TLRs. Ligand binding to TLR7 and 9 triggers conformational changes to potentiate GPCR signaling via MMP-9 activation and Gai subunits to induce Neul sialidase, which hydrolizes syalil residues linked to $\beta$-galattosidase, triggering TLRs dimeric complex formation and MyD88/TLR recruitment [124].

On the other hand, in murine macrophages the endotoxin lipoplysaccaride (LPS) binds to TLR4 and potentiates GPCR signaling via Gai proteins and MMP-9, inducing Neul sialidase activity. The Neu1-MMP-9 crosstalk in alliance with TLR4 and GPCR on cell surface generates a molecular signaling platform that is essential for ligand-induced TLR activation. The signaling paradigm suggests a conformational change of the receptor, as a result of ligand binding, to initiate GPCR signaling via Gai proteins and MMP-9 activation to induce Neu1. Activated Neu1 is tethered to TLR4 and hydrolizes syalil residues at the ectodomain of the receptor [125]. 


\section{RTK-Mediated GPCR Transactivation}

Signal transduction cascades triggered by several RTKs are mediated, at least in part, by transactivation of GPCRs, suggesting a reciprocal transactivation between the two classes of receptors. Molecular models of GPCR transactivation by RTK ligands depend on the nature of the GPCR-RTK partners and are similar to those employed by GPCR agonists to transactivate RTKs. In some cases, GPCR transactivation occurs in a ligand-dependent manner through synthesis and secretion of a ligand of the transactivated GPCR. This ligand activates the GPCR in an autocrine and/or paracrine manner [126-129]. In other GPCR-RTK partnerships, the transactivation of GPCRs by RTK agonists occurs in a ligand-independent manner and requires the formation of GPCR-RTK complexes, which might also arise from their interaction with intracellular scaffolding proteins, as well as the phosphorylation of the transactivated GPCRs [130]. Enzymatic activation and/or transcriptional up-regulation are required for the synthesis and the extracellular accumulation of GPCR ligands, upon RTK stimulation. For instance, S1P1 is transactivated by NGF as a consequence of production of S1P [7]. Stimulation with NGF triggers both sphingosine kinase 1 (SphK1) plasma membrane translocation and SphK1 activation, which enhances synthesis and secretion of S1P and in turn, S1P1 activation [7].

GPCR phosphorylation can represent a mechanism that contribute to cellular effects induced by RTK agonists. For instance, insulin promotes phosphorylation of $\beta 2$-adrenoceptors on a tyrosine residue, which does not transactivate $\beta 2$-adrenoceptors but results in an increase in receptor functional activity [131]. The modulation of $\beta 2$-adrenergic receptors function by insulin requires the coordinate action of at least three pathways [7] which involve (i) $\beta 2$-adrenoceptors phosphorylation on tyrosine residues mediated by the insulin receptor [132]; (ii) the activation of Akt/PKB pathway, which phosphorylates $\beta 2$-adrenergic receptors on serine residues [133] and (iii) the activation of c-Src by insulin, which leads to a further stimulation of phosphatidylinositol-3kinase (PI3K) [134]. IGF-I induces tyrosine phosphorylation of $\beta 2$-adrenoceptors at different sites than insulin [135]. Similarly, $\alpha 1 B$-adrenoceptor phosphorylation can be triggered by EGFR and PDGFR activation [136] and the actions of EGF and PDGF are prevented by PTX [137], indicating that the inhibition of G protein function alters RTK actions. The general mechanism contemplates an integrated signaling unit composed by RTKs and GPCRs, capable of responding to RTK agonists utilizing GPCRs as accessory elements and employing both, G proteins and the tyrosine phosphorylation pathways. This integrated signaling [98,138] can involve recruiting of intracellular protein kinases (c-Src or PI3K) or adaptor proteins ( $\beta$-arrestins, Grb2 or Gab1), which could facilitate the combined actions of RTKs and GPCRs (Figure 5). 
Figure 5. Ligand-independent RTK-mediated GPCR transactivation. The transactivation of GPCRs by RTK agonists can occur in a ligand-independent manner and requires the formation of GPCR-RTK complexes. RTK stimulation triggers GPCR transactivation through the generation of a molecular protein complex. Several proteins contribute to this event, such as c-Src, which promotes the phosphorylation of cytoplasmic tyrosines residues of GPCRs. This event is crucial for $\beta$-arrestin recruitment, which, in turns, promotes the internalization of the RTK/GPCR complex and intracellular signaling cascades.

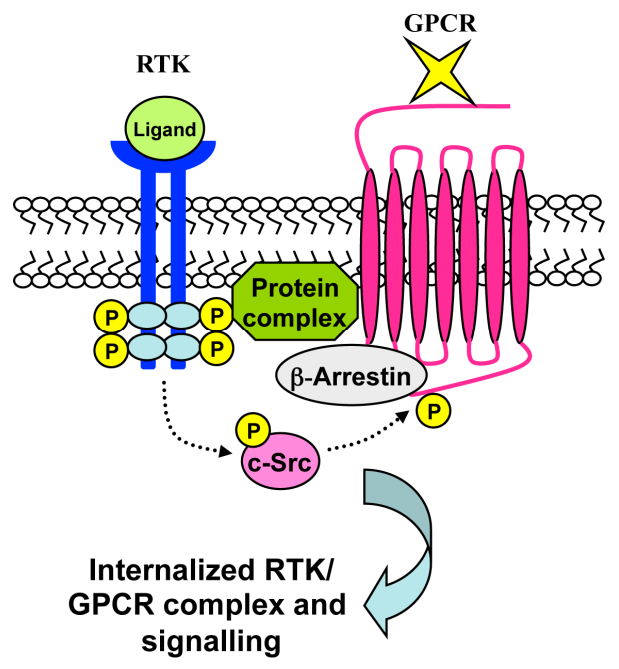

\section{Conclusions}

GPCR agonists act as efficient cellular growth factors in several cell types, activating a highly interconnected signaling network. Activated GPCRs interact with one or more G proteins, or trigger intracellular cascades through $\mathrm{G}$ protein-independent mechanisms. Furthermore, hetrotrimeric $\mathrm{G}$ proteins regulate monomeric $\mathrm{G}$ proteins, suggesting that heptahelical receptors act as part of multi-protein signaling complexes. RTKs form complexes with GPCRs, which can supply G-protein for use by RTKs and, in other cases, distinct RTKs can be directly associated with heterotrimeric G-proteins. Combinations of RTK inhibitors and GPCR-specific ligands that prevent Gi function can represent the most efficient method to inhibit signaling from RTK-GPCR platform complexes.

GPCRs transduce signals through both the synthesis of second messengers and the recruitment of non-receptor tyrosine kinases and/or RTKs on plasma membrane. GPCR-mediated RTK transactivation can occur by different molecular mechanisms which include ADAM- or MMP-dependent release of precursor forms of RTK agonists, activation of membrane associated non-receptor tyrosine kinases (Src, Lyn, Pyk, Fyn), and ROS generation, mainly through the activation of the NADPH oxidase complex. Nox proteins are the only enzymes that generate ROS in a highly regulated manner, suited to modulate intracellular cellular communication. Nox2, a member of the NADPH oxidase enzyme family, is activated by several GPCR agonists, by cytokines and by growth factors. The molecular mechanism for RTK transactivation can involve inactivation of PTPs by ROS which, in turn, induces an increase of protein tyrosine kinase activity. Targeting ROS-sensitive mechanisms with selective drugs and the further characterization of the molecular mechanisms involved in ROS-mediated signal transduction via RTK activation can provide new targets for adequate therapies. 
Many of the pathways triggered by GPCR agonists are also engaged by RTK ligands, providing broad changes of crosstalk between heterologous receptors. The crosstalk can occur at proximal level (receptor to receptor) and a high degree of selectivity and specificity is required for GPCR-mediated transactivation of a distinct RTK, or downstream of intracellular signaling pathways involving members of Src family tyrosine kinases, ERKs, p38MAPK, JNK and other kinases. The crosstalk can also occur between receptors belonging to the same family, as the case of the activation of IGF-1R which can induce EGFR transactivation and MAPK activation.

Autophosphorylated RTKs provide docking sites for the recruitment of signaling proteins via SH2 and PTB sites. Similarly, RTK-mediated phosphorylation of GPCRs induces the formation of SH2 sites on heptahelical receptors, providing the notion that RTKs can supply similar scaffold properties to GPCRs. These receptor-based signaling complexes differ among different cell types. GPCR transactivation by RTK agonists has been proved only for a few GPCR-RTK partnerships and needs to be generalized. In several human diseases over-expression of many RTKs, GPCRs and/or their enhanced activity, as well as increased levels of growth factors has been observed, which have been associated with increased cell proliferation and migration. Various pharmacological approaches have been developed to target RTKs in different human cancers. The dissection of the molecular mechanisms responsible of GPCR transactivation by RTK ligands might lead to the development of new drugs able to block RTK signaling and RTK-dependent GPCR transactivation, by antagonists or inverse agonists of the corresponding GPCRs.

GPCRs can also transactivate S/TK cell surface receptors, such as T $\beta$ RI which efficiently binds TGF- $\beta$. This observation suggests a possible shared mechanism of transactivation in which a GPCR inhibitor can prevent both tyrosine kinase and S/TK receptor transactivation. It is not clear if GPCR activation by multiple GPCR agonists transactivates many RTKs and S/TK receptors through the activation of multiple signaling cascades. The identification of specific molecular targets in these pathways, linked to specific human diseases, can provide new approaches for therapeutic intervention.

Crosstalk between GPCRs and RTKs provides wider changes for the identification of new drugs for the treatment of human diseases attributed to an increased level of growth factors or to modulation of RTKs activity, challenging current thinking in the definition of pharmacological targets.

\section{Acknowledgments}

This work has been supported by POR Campania FSE 2007-2013, Project CREME.

\section{Author Contributions}

Fabio Cattaneo, Germano Guerra and Melania Parisi collected and analyzed all the data on the transactivation mechanisms; Marta De Marinis drew the three tables included in the manuscript; Domenico Tafuri and Mariapia Cinelli projected and designed the five schematic pictures. Rosario Ammendola analyzed data and wrote the paper. All authors discussed the results and commented on the manuscript.

\section{Conflicts of Interest}

The authors declare no conflict of interest. 


\section{References}

1. Kamato, D.; Burch, M.L.; Osman, N.; Zheng, W.; Little, P.J. Therapeutic implications of endothelin and thrombin G-protein-coupled receptor transactivation of tyrosine and serine/threonine kinase cell surface receptors. J. Pharm. Pharmacol. 2013, 65, 465-473.

2. Schlessinger, J. Cell signaling by receptor tyrosine kinases. Cell 2000, 103, 211-225.

3. De Caestecker, M.P.; Parks, W.T.; Frank, C.J.; Castagnino, P.; Bottaro, D.P.; Roberts, A.B.; Lechleider, R.J. Smad2 transduces common signals from receptor serine-threonine and tyrosine kinases. Genes Dev. 1998, 12, 1587-1592.

4. Neves, S.R.; Ram, P.T.; Lyengar, R. G protein pathways. Science 2002, 296, 1636-1639.

5. George, A.J.; Hannan, R.D.; Thomas, W.G. Unravelling the molecular complexity of GPCR-mediated EGFR transactivation using functional genomics approaches. FEBS J. 2013, 280, 5258-5268.

6. Luttrell, L.M.; Lefkowitz, R.J. The role of $\beta$-arrestins in the termination and transduction of G-protein-coupled receptor signals. J. Cell Sci. 2002, 115, 455-465.

7. García-Sáinz, J.A.; Romero-Ávila, M.T.; Medina, L.D.C. Dissecting how receptor tyrosine kinases modulate G protein-coupled receptor function. Eur. J. Pharmacol. 2010, 648, 1-5.

8. Daub, H.; Weiss, F.U.; Wallasch, C.; Ullrich, A. Role of transactivation of the EGF receptor in signalling by G-protein-coupled receptors. Nature 1996, 6565, 557-560.

9. Leserer, M.; Gschwind, A.; Ullrich, A. Epidermal growth factor receptor signal transactivation. IUBMB Life 2000, 49, 405-409.

10. Pyne, N.J.; Pyne, S. Receptor tyrosine kinase-G-protein-coupled receptor signalling platforms: Out of the shadow? Trends Pharmacol. Sci. 2011, 8, 443-450.

11. Burch, M.L.; Osman, N.; Getachew, R.; Al-Aryahi, S.; Poronnik, P.; Zheng, W.; Hill, M.A.; Little, P.J. $\mathrm{G}$ protein coupled receptor transactivation: Extending the paradigm to include serine/threonine kinase receptors. Int. J. Biochem. Cell Biol. 2012, 44, 722-727.

12. Prenzel, N.; Zwick, E.; Daub, H.; Leserer, M.; Abraham, R.; Wallasch, C.; Ullrich, A. EGF receptor transactivation by G-protein-coupled receptors requires metalloproteinase cleavage of proHB-EGF. Nature 1999, 6764, 884-888.

13. Andreev, J.; Galisteo, M.L.; Kranenburg, O.; Logan, S.K.; Chiu, E.S.; Okigaki, M.; Cary, L.A.; Moolenaar, W.H.; Schlessinger, J. Src and Pyk2 mediate G-protein-coupled receptor activation of epidermal growth factor receptor (EGFR) but are not required for coupling to the mitogen-activated protein (MAP) kinase signaling cascade. J. Biol. Chem. 2001, 276, 20130-20135.

14. Esposito, G.; Perrino, C.; Cannavo, A.; Schiattarella, G.G.; Borgia, F.; Sannino, A.; Pironti, G.; Gargiulo, G.; di Serafino, L.; Franzone, A.; et al. EGFR trans-activation by urotensin II receptor is mediated by $\beta$-arrestin recruitment and confers cardioprotection in pressure overload-induced cardiac hypertrophy. Basic Res. Cardiol. 2011, 106, 577-589.

15. Gesty-Palmer, D.; Yuan, L.; Martin, B.; Wood, W.H.; Lee, M.H.; Janech, M.G.; Tsoi, L.C.; Zheng, W.J.; Luttrell, L.M.; Maudsley, S. $\beta$-Arrestin-selective G protein-coupled receptor agonists engender unique biological efficacy in vivo. Mol. Endocrinol. 2013, 27, 296-314.

16. El-Shewy, H.M.; Abdel-Samie, S.A.; Al Qalam, A.M.; Lee, M.H.; Kitatani, K.; Anelli, V.; Jaffa, A.A.; Obeid, L.M.; Luttrell, L.M. Phospholipase C and protein kinase C- $\beta 2$ mediate insulin-like growth factor II-dependent sphingosine kinase 1 activation. Mol. Endocrinol. 2011, 25, 2144-2156. 
17. Chen, J.; Chen, J.K.; Harris, R.C. Angiotensin II induces epithelial-to-mesenchymal transition in renal epithelial cells through reactive oxygen species/Src/caveolin-mediated activation of an epidermal growth factor receptor-extracellular signal-regulated kinase signaling pathway. Mol. Cell. Biol. 2012, 32, 981-991.

18. Tilley, D.G.; Kim, I.M.; Patel, P.A.; Violin, J.D.; Rockman, H.A. Arrestin mediates $\beta 1$-adrenergic receptor epidermal growth factor receptor interaction and downstream signaling. J. Biol. Chem. 2009, 284, 20375-20386.

19. Page-McCaw, A.; Ewald, A.J.; Werb, Z. Matrix metalloproteinases and the regulation of tissue remodelling. Nat. Rev. Mol. Cell Biol. 2007, 8, 221-233.

20. Klein, T.; Bischoff, R. Physiology and pathophysiology of matrix metalloproteases. Amino Acids 2011, 41, 271-290.

21. Sternlicht, M.D.; Werb, Z. How matrix metalloproteinases regulate cell behavior. Annu. Rev. Cell Dev. Biol. 2001, 17, 463-516.

22. Uchiyama-Tanaka, Y.; Matsubara, H.; Mori, Y.; Kosaki, A.; Kishimoto, N.; Amano, K.; Higashiyama S.; Iwasaka, T. Involvement of HB-EGF and EGF receptor transactivation in TGF- $\beta$-mediated fibronectin expression in mesangial cells. Kidney Int. 2002, 62, 799-808.

23. Kleine-Brueggeney, M.; Gradinaru, I.; Babaeva, E.; Schwinn, D.A.; Oganesian, A. Alpha1a-Adrenoceptor genetic variant induces cardiomyoblast-to-fibroblast-like cell transition via distinct signaling Pathways. Cell. Signal. 2014, 26, 1985-1997.

24. Gilmour, A.M.; Abdulkhalek, S.; Cheng, T.S.; Alghamdi, F.; Jayanth, P.; O'Shea, L.K.; Geen, O.; Arvizu, L.A.; Szewczuk, M.R. A novel epidermal growth factor receptor-signaling platform and its targeted translation in pancreatic cancer. Cell. Signal. 2013, 25, 2587-2603.

25. Nagareddy, P.R.; Chow, F.L.; Hao, L.; Wang, X.; Nishimura, T.; MacLeod, K.M.; McNeill, J.H.; Fernandez-Patron, C. Maintenance of adrenergic vascular tone by MMP transactivation of the EGFR requires PI3K and mitochondrial ATP synthesis. Cardiovasc. Res. 2009, 84, 368-377.

26. Gschwind, A.; Prenzel, N.; Ullrich, A. Lysophosphatidic acid-induced squamous cell carcinoma cell proliferation and motility involves epidermal growth factor receptor signal transactivation. Cancer Res. 2002, 62, 6329-6336.

27. Tanimoto, T.; Jin, Z.G.; Berk, B.C. Transactivation of vascular endothelial growth factor (VEGF) receptor Flk-1/KDR is involved in sphingosine 1-phosphate-stimulated phosphorylation of Akt and endothelial nitric-oxide synthase (eNOS) J. Biol. Chem. 2002, 277, 42997-43001.

28. Thuringer, D.; Maulon, L.; Frelin, C. Rapid transactivation of the vascular endothelial growth factor receptor KDR/Flk-1 by the bradykinin B2 receptor contributes to endothelial nitric-oxide synthase activation in cardiac capillary endothelial cells. J. Biol. Chem. 2002, 277, 2028-2032.

29. Tsai, C.L.; Chen, W.C.; Lee, I.T.; Chi, P.L.; Cheng, S.E.; Yang, C.M. c-Src-dependent transactivation of PDGFR contributes to TNF- $\alpha$-induced MMP-9 expression and functional impairment in osteoblasts. Bone 2014, 60, 186-197.

30. Yang, C.M.; Hsieh, H.L.; Yao, C.C.; Hsiao, L.D.; Tseng, C.P.; Wu, C.B. Protein kinase C- $\delta$ transactivates platelet-derived growth factor receptor- $\alpha$ in mechanical strain-induced collagenase 3 (matrix metalloproteinase-13) expression by osteoblast-like cells. J. Biol. Chem. 2009, 284, 26040-26050. 
31. Carbajal, L.; Biswas, A.; Niswander, L.M.; Prizant, H.; Hammes, S.R. GPCR/EGFR cross talk is conserved in gonadal and adrenal steroidogenesis but is uniquely regulated by matrix metalloproteinases 2 and 9 in the ovary. Mol. Endocrinol. 2011, 25, 1055-1065.

32. Roelle, S.; Grosse, R.; Aigner, A.; Krell, H.W.; Czubayko, F.; Gudermann, T. Matrix metalloproteinases 2 and 9 mediate epidermal growth factor receptor transactivation by gonadotropin-releasing hormone. J. Biol. Chem. 2003, 278, 47307-47318.

33. Hao, L.; Du, M.; Lopez-Campistrous, A.; Fernandez-Patron, C. Agonist-induced activation of matrix metalloproteinase-7 promotes vasoconstriction through the epidermal growth factor-receptor pathway. Circ. Res. 2004, 94, 68-76.

34. Anchaa, H.R.; Kurella, R.R.; Stewart, C.A.; Damerac, G.; Ceresa, B.P.; Harty R.F. Histamine stimulation of MMP-1 (collagenase-1) secretion and gene expression in gastric epithelial cells: Role of EGFR transactivation and the MAP kinase pathway. Int. J. Biochem. Cell Biol. 2007, 39, 2143-2152.

35. Huang, C.-Y.; Lin, H.-J.; Chen, H.-S.; Cheng, S.-Y.; Hsu, H.-C.; Tang C.-H. Thrombin promotes matrix metalloproteinase-13 expression through the PKCס/c-Src/EGFR/PI3K/Akt/AP-1 signaling pathway in human chondrocytes. Mediat. Inflamm. 2013, 2013, 326041.

36. Yoo, J.; Rodriguez Perez, C.E.; Nie, W.; Sinnett-Smith J.; Rozengurt E. TNF- $\alpha$ and LPA promote synergistic expression of COX-2 in human colonic myofibroblasts: Role of LPA-mediated transactivation of upregulated EGFR. BMC Gastroenterol. 2013, 13, 90.

37. Xu, K.P.; Yin, J.; Yu, F.S. Lysophosphatidic acid promoting corneal epithelial wound healing by transactivation of epidermal growth factor receptor. Investig. Ophthalmol. Vis. Sci. 2007, 48, 636-643.

38. Klein, T.; Bischoff, R. Active metalloproteases of the a disintegrin and metalloprotease (ADAM) family: Biological function and structure. J. Proteome Res. 2011, 10, 17-33.

39. Murphy, G. Regulation of the proteolytic disintegrin metalloproteinases, the 'Sheddases'. Semin. Cell Dev. Biol. 2009, 20, 138-145.

40. Dang, M.; Armbruster, N.; Miller, M.A.; Cermeno, E.; Hartmann, M.; Bell, G.W.; Root, D.E.; Lauffenburger, D.A.; Lodish, H.F.; Herrlich, A. Regulated ADAM17-dependent EGF family ligand release by substrate-selecting signaling pathways. Proc. Natl. Acad. Sci. USA 2013, 110, 9776-9781.

41. Ohtsu, H.; Dempsey, P.J.; Educhi, S. ADAMs as mediators of EGF receptor transactivation by Gprotein-coupled receptors. Am. J. Physiol. Cell Physiol. 2006, 291, C1-C10.

42. Thomas, W.G.; Brandenburger, Y.; Autelitano, D.J.; Pham, T.; Qian, H.; Hannan, R.D. Adenoviral-directed expression of the type 1A angiotensin receptor promotes cardiomyocyte hypertrophy via transactivation of the epidermal growth factor receptor. Circ. Res. 2002, 90, 135-142.

43. Schafer, B.; Gschwind, A.; Ullrich, A. Multiple G-protein-coupled receptor signals converge on the epidermal growth factor receptor to promote migration and invasion. Oncogene 2004, 23, 991-999.

44. Gschwind, A.; Hart, S.; Fischer, O.M.; Ullrich, A. TACE cleavage of proamphiregulin regulates GPCR-induced proliferation and motility of cancer cells. EMBO J. 2003, 22, 2411-2421. 
45. Chalaris, A.; Rabe, B.; Paliga, K.; Lange, H.; Laskay, T.; Fielding, C.A.; Jones, S.A.; Rose-John, S.; Scheller, J. Apoptosis is a natural stimulus of IL6R shedding and contributes to the proinflammatory trans-signaling function of neutrophils. Blood 2007, 110, 1748-1755.

46. Pietri, M.; Schneider, B.; Mouillet-Richard, S.; Ermonval, M.; Mutel, V.; Launay, J.M.; Kellermann, O. Reactive oxygen species-dependent TNF- $\alpha$ converting enzyme activation through stimulation of 5-HT2B and $\alpha 1 \mathrm{D}$ autoreceptors in neuronal cells. FASEB J. 2005, 19, 1078-1087.

47. Camden, J.M.; Schrader, A.M.; Camden, R.E.; Gonzalez, F.A.; Erb, L.; Seye, C.I.; Weisman, G.A. P2Y2 nucleotide receptors enhance $\alpha$-secretase-dependent amyloid precursor protein processing. J. Biol. Chem. 2005, 280, 18696-18702.

48. Itoh, Y.; Joh, T.; Tanida, S.; Sasaki, M.; Kataoka, H.; Itoh, K.; Oshima, T.; Ogasawara, N.; Togawa, S.; Wada, T.; et al. IL-8 promotes cell proliferation and migration through metalloproteinase-cleavage proHB-EGF in human colon carcinoma cells. Cytokine 2005, 29, 275-282.

49. Myers, T.J.; Brennaman, L.H.; Stevenson, M.; Higashiyama, S.; Russell, W.E.; Lee, D.C.; Sunnarborg, S.W. Mitochondrial reactive oxygen species mediate GPCR-induced TACE/ADAM17-dependent transforming growth factor- $\alpha$ shedding. Mol. Biol. Cell 2009, 24, 5236-5249.

50. Lee, S.J.; Seo, K.W.; Yun, M.R.; Bae, S.S.; Lee, W.S; Hong, K.W.; Kim, C.D. 4-Hydroxynonenal enhances MMP-2 production in vascular smooth muscle cells via mitochondrial ROS-mediated activation of the Akt/NF- $\mathrm{BB}$ signaling pathways. Free Radic. Biol. Med. 2008, 45, 1487-1492.

51. Fischer, O.M.; Hart, S.; Gschwind, A.; Prenzel, N.; Ullrich, A. Oxidative and osmotic stress signaling in tumor cells is mediated by ADAM proteases and heparin-binding epidermal growth factor. Mol. Cell. Biol. 2004, 24, 5172-5183.

52. Frank, G.D.; Eguchi, S. Activation of tyrosine kinases by reactive oxygen species in vascular smooth muscle cells: Significance and involvement of EGF receptor transactivation by angiotensin II. Antioxid. Redox Signal. 2003, 5, 771-780.

53. Adrain, C.; Freeman, M. Regulation of receptor tyrosine kinase ligand processing. Cold Spring Harb. Perspect. Biol. 2014, 6, a020768.

54. Finkel, T. Redox-dependent signal transduction. FEBS Lett. 2000, 476, 52-54.

55. Derbre, F.; Ferrando, B.; Gomez-Cabrera, M.C.; Sanchis-Gomar, F.; Martinez-Bello, V.E.; Olaso-Gonzalez, G.; Diaz, A.; Gratas-Delamarche, A.; Cerda, M.; Viña, J. Inhibition of xanthine oxidase by allopurinol prevents skeletal muscle atrophy: Role of p38 MAPKinase and E3 ubiquitin ligases. PLoS One 2012, 7, e46668.

56. Rhee, S.G.; Bae, Y.S.; Lee, S.R.; Kwon, J. Hydrogen peroxide: A key messenger that modulates protein phosphorylation through cysteine oxidation. Sci. Signal. 2000, 2000, pe1.

57. Zhang, M.; Shah, A.M. ROS signalling between endothelial cells and cardiac cells. Cardiovasc. Res. 2014, 102, 249-257.

58. Bedard, K.; Krause, K.H. The NOX family of ROS-generating NADPH oxidases: Physiology and pathophysiology. Physiol. Rev. 2007, 87, 245-313. 
59. Brandes, R.P.; Weissmann, N.; Schröder, K. NADPH oxidases in cardiovascular disease. Free Radic. Biol. Med. 2010, 49, 687-706.

60. Lambeth, J.D. Nox/Duox family of nicotinamide adenine dinucleotide (phosphate) oxidases. Curr. Opin. Hematol. 2002, 9, 11-17.

61. Finkel, T. Oxidant signals and oxidative stress. Curr. Opin. Cell Biol. 2003, 15, 247-254.

62. Frank, G.D.; Eguchi, S.; Inagami, T.; Motley, E.D. N-Acetylcysteine inhibits angiotensin II-mediated activation of extracellular signal-regulated kinase and epidermal growth factor receptor. Biochem. Biophys. Res. Commun. 2001, 280, 1116-1119.

63. Frank, G.D.; Mifune, M.; Inagami, T.; Ohba, M.; Sasaki, T.; Higashiyama, S.; Dempsey, P.J.; Eguchi, S. Distinct mechanisms of receptor and nonreceptor tyrosine kinase activation by reactive oxygen species in vascular smooth muscle cells: Role of metalloprotease and protein kinase C- $\delta$. Mol. Cell. Biol. 2003, 23, 1581-1589.

64. Miller, F.J. Jr.; Chu, X.; Stanic, B.; Tian, X.; Sharma, R.V.; Davisson, R.L.; Lamb, F.S. A differential role for endocytosis in receptor-mediated activation of Nox1. Antioxid. Redox Signal. 2010, 12, 583-593.

65. Jagadeesha, D.K.; Takapoo, M.; Banfi, B.; Bhalla, R.C.; Miller, F.J., Jr. Nox1 transactivation of epidermal growth factor receptor promotes $\mathrm{N}$-cadherin shedding and smooth muscle cell migration. Cardiovasc. Res. 2012, 93, 406-413.

66. Kruk, J.S.; Vasefi, M.S.; Heikkila, J.J.; Beazely, M.A. Reactive oxygen species are required for 5-HT-induced transactivation of neuronal platelet-derived growth factor and TrkB receptors, but not for ERK1/2 activation. PLoS One 2013, 8, e77027.

67. Cattaneo, F.; Iaccio, A.; Guerra, G.; Montagnani, S.; Ammendola, R. NADPH-oxidase-dependent reactive oxygen species mediate EGFR transactivation by FPRL1 in WKYMVm-stimulated human lung cancer cells. Free Radic. Biol. Med. 2011, 51, 1126-1136.

68. Seshiah, P.N.; Weber, D.S.; Rocic, P.; Valppu, L.; Taniyama, Y.; Griendling, K.K. Angiotensin II stimulation of NAD(P)H oxidase activity: Upstream mediators. Circ. Res. 2002, 91, 406-413.

69. Chen, K.; Vita, J.A.; Berk, B.C.; Keaney, J.F., Jr. c-Jun $N$-terminal kinase activation by hydrogen peroxide in endothelial cells involves SRC-dependent epidermal growth factor receptor transactivation. J. Biol. Chem. 2001, 276, 16045-16050.

70. Rozengurt E. Mitogenic signaling pathways induced by G protein-coupled receptors. J. Cell. Physiol. 2007, 213, 589-602.

71. Parekh, A.B.; Putney, J.W., Jr. Store-operated calcium channels. Physiol. Rev. 2005, 85, 757-810.

72. Eguchi, S.; Numaguchi, K.; Iwasaki, H.; Matsumoto, T.; Yamakawa, T.; Utsunomiya, H.; Motley, E.D.; Kawakatsu, H.; Owada, K.M.; Hirata, Y.; et al. Calcium-dependent epidermal growth factor receptor transactivation mediates the angiotensin II-induced mitogen-activated protein kinase activation in vascular smooth muscle cells. J. Biol. Chem. 1998, 273, 8890-8896.

73. Frank, G.D.; Motley, E.D.; Inagami, T.; Eguchi, S. PYK2/CAK $\beta$ represents a redox-sensitive tyrosine kinase in vascular smooth muscle cells. Biochem. Biophys. Res. Commun. 2000, 270, $761-765$. 
74. Lee, S.H.; Na, S.I.; Heo, J.S.; Kim, M.H.; Kim, Y.H.; Lee, M.Y.; Kim, S.H.; Lee, Y.J.; Han, H.J. Arachidonic acid release by $\mathrm{H}_{2} \mathrm{O}_{2}$ mediated proliferation of mouse embryonic stem cells: Involvement of $\mathrm{Ca}^{2+} / \mathrm{PKC}$ and MAPKs-induced EGFR transactivation. J. Cell. Biochem. 2009, 106, 787-797.

75. Iaccio, A.; Collinet, C.; Gesualdi, N.M.; Ammendola, R. Protein kinase C- $\alpha$ and $-\delta$ are required for NADPH oxidase activation in WKYMVm-stimulated IMR90 human fibroblasts. Arch. Biochem. Biophys. 2007, 459, 288-294.

76. Saito, S.; Frank, G.D.; Mifune, M.; Ohba, M.; Utsunomiya, H.; Motley, E.D.; Inagami, T.; Eguchi, S. Ligand-independent trans-activation of the platelet-derived growth factor receptor by reactive oxygen species requires protein kinase $\mathrm{C}-\delta$ and c-Src. J. Biol. Chem. 2002, 277, 44695-44700.

77. Fischer, O.M.; Giordano, S.; Comoglio, P.M.; Ullrich, A. Reactive oxygen species mediate Met receptor transactivation by $\mathrm{G}$ protein-coupled receptors and the epidermal growth factor receptor in human carcinoma cells. J. Biol. Chem. 2004, 279, 28970-28978.

78. Pavone, L.M.; Cattaneo, F.; Rea, S.; de Pasquale, V.; Spina, A.; Sauchelli, E.; Mastellone, V.; Ammendola, R. Intracellular signaling cascades triggered by the NK1 fragment of hepatocyte growth factor in human prostate epithelial cell line PNT1A. Cell Signal. 2011, 23, 1961-1971.

79. Cattaneo, F.; Parisi, M.; Ammendola, R. WKYMVm-induced cross-talk between FPR 2 and HGF receptor in human prostate epithelial cell line PNT1A. FEBS Lett. 2013, 587, 1536-1542.

80. El Zein, N.; D'Hondt, S.; Sariban, E. Crosstalks between the receptors tyrosine kinase EGFR and TrkA and the GPCR, FPR, in human monocytes are essential for receptors-mediated cell activation. Cell Signal. 2010, 22, 1437-1447.

81. Luttrell, D.K.; Luttrell, L.M. Not so strange bedfellows: G-protein-coupled receptors and Src family kinases. Oncogene 2004, 23, 7969-7978.

82. Fan, G.; Shumay, E.; Malbon, C.C.; Wang, H. c-Src tyrosine kinase binds the $\beta 2$-adrenergic receptor via phospho-Tyr-350, phosphorylates G-protein-linked receptor kinase 2, and mediates agonist-induced receptor desensitization. J. Biol. Chem. 2001, 276, 13240-13247.

83. Amorino, G.P.; Deeble, P.D.; Parsons, S.J. Neurotensin stimulates mitogenesis of prostate cancer cells through a novel c-Src/Stat5b pathway. Oncogene 2007, 26, 745-756.

84. Rodrìguez-Fernàndez, J.L.; Rozengurt, E. Bombesin, bradykinin, vasopressin, and phorbol esters rapidly and transiently activate Src family tyrosine kinases in Swiss 3T3 cells. Dissociation from tyrosine phosphorylation of p125 focal adhesion kinase. J. Biol. Chem. 1996, 271, 27895-27901.

85. Pierce, K.L.; Tohgo, A.; Ahn, S.; Field, M.E.; Luttrell, L.M.; Lefkowitz, R.J. Epidermal growth factor (EGF) receptor dependent ERK activation by $\mathrm{G}$ protein-coupled receptors: A co-culture system for identifying intermediates upstream and downstream of heparin-binding EGF shedding. J. Biol. Chem. 2001, 276, 23155-23160.

86. Shah, B.H.; Catt, K.J. Calcium-independent activation of extracellularly regulated kinases 1 and 2 by angiotensin II in hepatic C9 cells: Roles of protein kinase C $\delta$, Src/proline-rich tyrosine kinase 2, and epidermal growth factor receptor trans-activation. Mol. Pharmacol. 2002, 61, 343-351.

87. Oligny-Longpré, G.; Corbani, M.; Zhou, J.; Hogue, M.; Guillon, G.; Bouvier, M. Engagement of $\beta$-arrestin by transactivated insulin-like growth factor receptor is needed for V2 vasopressin receptor-stimulated ERK1/2 activation. Proc. Natl. Acad. Sci. USA 2012, 109, E1028-E1037. 
88. Iaccio, A.; Cattaneo, F.; Mauro, M.; Ammendola, R. FPRL1-mediated induction of superoxide in LL-37-stimulated IMR90 human fibroblast. Arch. Biochem. Biophys. 2009, 481, 94-100.

89. Cattaneo, F.; Guerra, G.; Ammendola, R. Expression and signaling of formyl-peptide receptors in the brain. Neurochem. Res. 2010, 35, 2018-2026.

90. Cattaneo, F.; Parisi, M.; Ammendola, R. Distinct signaling cascades elicited by different formyl peptide receptor 2 (FPR2) agonists. Int. J. Mol. Sci. 2013, 14, 7193-7230.

91. Rajagopal, R.; Chao, M.V. A role for Fyn in Trk receptor transactivation by G-protein-coupled receptor signaling. Mol. Cell. Neurosci. 2006, 33, 36-46.

92. Kruk, J.S.; Vasefi, M.S.; Liu, H.; Heikkila, J.J.; Beazely, M.A. 5-HT1A receptors transactivate the platelet-derived growth factor receptor type $\beta$ in neuronal cells. Cell Signal. 2013, 25, 133-143.

93. Waters, C.M.; Connell, M.C.; Pyne, S.; Pyne, N.J. c-Src is involved in regulating signal transmission from PDGF $\beta$ receptor-GPCR(s) complexes in mammalian cells. Cell Signal. 2005, $17,263-277$.

94. Lei, H.; Kazlauskas, A. A reactive oxygen species-mediated, self-perpetuating loop persistently activates platelet-derived growth factor receptor $\alpha$. Mol. Cell. Biol. 2014, 34, 110-122.

95. Waters, C.; Sambi, B.; Kong, K.C.; Thompson, D.; Pitson, S.M.; Pyne, S.; Pyne, N.J. Sphingosine 1-phosphate and platelet-derived growth factor (PDGF) act via PDGF $\beta$ receptor-sphingosine 1-phosphate receptor complexes in airway smooth muscle cells. J. Biol. Chem. 2003, 278, 6282-6290.

96. Long, J.S.; Natarajan, V.; Tigyi, G.; Pyne, S.; Pyne, N.J. The functional PDGF $\beta$ receptor-S1P1 receptor signalling complex is involved in regulating migration of mouse embryonic fibroblasts in response to platelet derived growth factor. Prostaglandins Other Lipid Mediat. 2006, 80, 74-80.

97. Maudsley, S.; Pierce, K.L.; Zamah, A.M.; Miller, W.E.; Ahn, S.; Daaka, Y.; Lefkowitz, R.J.; Luttrell, L.M. The $\beta 2$-adrenergic receptor mediates extracellular signal-regulated kinase activation via assembly of a multi-receptor complex with the epidermal growth factor receptor. J. Biol. Chem. 2000, 275, 9572-9580.

98. Slomiany, B.L.; Slomiany, A. Gastric mucin secretion in response to $\beta$-adrenergic G-protein-coupled receptor activation is mediated by Src kinase-dependent epidermal growth factor receptor transactivation. J. Physiol. Pharmacol. 2005, 56, 247-258.

99. Delcourt, N.; Thouvenot, E.; Chanrion, B.; Galéotti, N.; Jouin, P.; Bockaert, J.; Marin, P. PACAP type 1 receptor transactivation is essential for IGF-1 receptor signalling and anti-apoptotic activity in neurones. EMBO J. 2007, 26, 1542-1551.

100. Moughal, N.A.; Waters, C.; Sambi, B.; Pyne, S.; Pyne, N.J. Nerve growth factor signalling involves interaction between the TrkA receptor and LPA receptor 1 systems: Nuclear translocation of the LPA receptor 1 and TrkA receptors in pheochromocytoma 12 cells. Cell Signal. 2004, 16, 127-136.

101. Bergelin, N.; Löf, C.; Balthasar, S.; Kalhori, V.; Törnquist, K. S1P1 and VEGFR-2 form a signalling complex with extracellularly regulated kinase $1 / 2$ and protein kinase $\mathrm{C}-\alpha$ regulating ML-1 thyroid carcinoma cell migration. Endocrinology 2010, 151, 2994-3005.

102. Wetzker, R.; Böhmer, F.D. Transactivation joins multiple tracks to the ERK/MAPK cascade. Nat. Rev. Mol. Cell Biol. 2003, 4, 651-657. 
103. Kodama, H.; Fukuda, K.; Takahashi, T.; Sano, M.; Kato, T.; Tahara, S.; Hakuno, D.; Sato, T.; Manabe, T.; Konishi, F.; et al. Role of EGF receptor and Pyk2 in endothelin-1-induced ERK activation in rat cardiomyocytes. J. Mol. Cell. Cardiol. 2002, 34, 139-150.

104. Akekawatchai, C; Holland, J.D.; Kochetkova, M.; Wallace J.C.; McColl, S.R. Transactivation of CXCR4 by the insulin-like growth factor-1receptor (IGF-1R) in human MDA-MB-231 breast cancer epithelial cells. J. Biol. Chem. 2005, 280, 39701-39708.

105. Shan, D.; Chen, L.; Wang, D.; Tan, Y.C.; Gu, J.L.; Huang, X.Y. The G protein Ga13 is required for growth factor-induced cell migration. Dev. Cell 2006, 10, 707-718.

106. Rakhit, S.; Pyne, S.; Pyne, N.J. Nerve growth factor stimulation of p42/p44 mitogen activated protein kinase in PC12 cells: Role of $\mathrm{G}_{\mathrm{i} / \mathrm{o}}, \mathrm{G}$ protein coupled receptor kinase 2, b-arrestin I, and endocytic processing. Mol. Pharmacol. 2001, 60, 63-70.

107. Dalle, S.; Imamura, T.; Rose, D.W.; Worrall, D.S.; Ugi, S.; Hupfeld, C.J.; Olefsky, J.M. Insulin induces heterologous desensitization of $\mathrm{G}$ protein-coupled receptor and insulin-like growth factor I signalling by downregulating $\beta$-arrestin-1. Mol. Cell. Biol. 2002, 22, 6272-6285.

108. Gschwind, A.; Zwick, E.; Prenzel, N.; Leserer, M.; Ullrich, A. Cell communication networks: Epidermal growth factor receptor transactivation as the paradigm for interreceptor signal transmission. Oncogene 2001, 20, 1594-1600.

109. Noma, T.; Lemaire, A.; Naga Prasad, S.V.; Barki-Harrington, L.; Tilley, D.G.; Chen, J.; le Corvoisier, P.; Violin, J.D.; Wei, H.; Lefkowitz, R.J.; et al. $\beta$-Arrestin-mediated $\beta 1$-adrenergic receptor transactivation of the EGFR confers cardioprotection. J. Clin. Investig. 2007, 117, 2445-2458.

110. Zajac, M.; Law, J.; Cvetkovic, D.D.; Pampillo, M.; McColl, L.; Pape, C.; di Guglielmo, G.M.; Postovit, L.M.; Babwah, A.V.; Bhattacharya, M. GPR54 (KISS1R) transactivates EGFR to promote breast cancer cell invasiveness. PLoS One 2011, doi:10.1371/journal.pone.0021599.

111. Zheng, H.; Worrall, C.; Shen, H.; Issad, T.; Seregard, S.; Girnita, A.; Girnita, L. Selective recruitment of $\mathrm{G}$ protein-coupled receptor kinases (GRKs) controls signaling of the insulin-like growth factor 1 receptor. Proc. Natl. Acad. Sci. USA 2012, 109, 7055-7060.

112. Spartà, A.; Baiula, M.; Campbell, G.; Spampinato, S. $\beta$-Arrestin 2-mediated heterologous desensitization of IGF-IR by prolonged exposure of SH-SY5Y neuroblastoma cells to a mu opioid agonist. FEBS Lett. 2010, 584, 3580-3586.

113. Ryu, J.M.; Baek, Y.B.; Shin, M.S.; Park, J.H.; Park, S.H.; Lee, J.H.; Han, H.J. Sphingosine-1phosphate-induced Flk-1 transactivation stimulates mouse embryonic stem cell proliferation through S1P1/S1P3-dependent $\beta$-arrestin/c-Src pathways. Stem Cell Res. 2014, 12, 69-85.

114. Little, P.J.; Burch, M.L.; Al-Aryahi, S.; Zheng, W. The paradigm of G protein receptor transactivation: A mechanistic definition and novel example. Sci. World J. 2011, 11, 709-714.

115. Burch, M.L.; Ballinger, M.L.; Yang, S.N.; Getachew, R.; Itman, C.; Loveland, K.; Osman, N.; Little, P.J. Thrombin stimulation of proteoglycan synthesis in vascular smooth muscle is mediated by protease-activated receptor-1 transactivation of the transforming growth factor $\beta$ type I receptor. J. Biol. Chem. 2010, 285, 26798-26805.

116. Xu, M.Y.; Porte, J.; Knox, A.J.; Weinreb, P.H.; Maher, T.M.; Violette, S.M.; McAnulty, R.J.; Sheppard, D.; Jenkins, G. Lysophosphatidic acid induces $\alpha \mathrm{v} \beta 6$ integrin-mediated TGF- $\beta$ activation via the $\mathrm{LPA}_{2}$ receptor and the small $\mathrm{G}$ protein $\mathrm{G} \alpha_{\mathrm{q}}$. Am. J. Pathol. 2009, 174, 1264-1279. 
117. Jenkins, R.G.; Su, X.; Su, G.; Scotton, C.J.; Camerer, E.; Laurent, G.J.; Davis, G.E.; Chambers, R.C.; Matthay, M.A.; Sheppard, D. Ligation of protease-activated receptor 1 enhances $\alpha_{v} \beta 6$ integrin-dependent TGF- $\beta$ activation and promotes acute lung injury. J. Clin. Investig. 2006, 116, 1606-1614.

118. Burch, M.L.; Getachew, R.; Osman, N.; Febbraio, M.A.; Little, P.J. Thrombin-mediated proteoglycan synthesis utilizes both protein-tyrosine kinase and serine/threonine kinase receptor transactivation in vascular smooth muscle cells. J. Biol. Chem. 2013, 288, 7410-7419.

119. Belmadani, S.; Zerfaoui, M.; Boulares, H.A.; Palen, D.I.; Matrougui, K. Microvessel vascular smooth muscle cells contribute to collagen type I deposition through ERK1/2 MAP kinase, $\alpha_{\mathrm{v}} \beta_{3}$-integrin, and TGF- $\beta 1$ in response to ANG II and high glucose. Am. J. Physiol. Heart Circ. Physiol. 2008, 295, H69-H76.

120. Liu, Y.; Ren W.; Warburton, R.; Toksoz, D.; Fanburg, B.L. Serotonin induces Rho/ROCK-dependent activation of Smads 1/5/8 in pulmonary artery smooth muscle cells. FASEB J. 2009, 23, 2299-2306.

121. Shi, G.X.; Harrison, K.; Han, S.B.; Moratz, C.; Kehrl, J.H. Toll-like receptor signaling alters the expression of regulator of $\mathrm{G}$ protein signaling proteins in dendritic cells: Implications for G protein-coupled receptor signalling. J. Immunol. 2004, 172, 5175-5184.

122. Abdulkhalek, S.; Guo, M.; Amith, S.R.; Jayanth, P.; Szewczuk, M.R. G-protein coupled receptor agonists mediate Neu1 sialidase and matrix metalloproteinase- 9 cross-talk to induce transactivation of TOLL-like receptors and cellular signaling. Cell Signal. 2012, 24, 2035-2042.

123. Amith, S.R.; Jayanth, P.; Finlay, T.; Franchuk, S.; Gilmour, A.; Abdulkhalek, S.; Szewczuk, M.R. Detection of Neu1 sialidase activity in regulating Toll-like receptor activation. J. Vis. Exp. 2010, 43, 2142.

124. Abdulkhalek, S.; Szewczuk, M.R. Neu1 sialidase and matrix metalloproteinase-9 cross-talk regulates nucleic acid-induced endosomal TOLL-like receptor-7 and -9 activation, cellular signaling and pro-inflammatory responses. Cell Signal. 2013, 25, 2093-2105.

125. Abdulkhalek, S.; Amith, S.R.; Franchuk, S.L.; Jayanth, P.; Guo, M.; Finlay, T.; Gilmour, A.; Guzzo, C.; Gee, K.; Beyaert, R.; et al. Neu1 sialidase and matrix metalloproteinase-9 cross-talk is essential for Toll-like receptor activation and cellular signaling. J. Biol. Chem. 2011, 286, 36532-36549.

126. Hobson, J.P.; Rosenfeldt, H.M.; Barak, L.S.; Olivera, A.; Poulton, S.; Caron, M.G.; Milstien, S.; Spiegel, S. Role of the sphingosine-1-phosphate receptor EDG-1 in PDGF-induced cell motility. Science 2001, 291, 1800-1803.

127. Mira, E.; Lacalle, R.A.; González, M.A.; Gómez-Moutón, C.; Abad, J.L.; Bernad, A.; Martínez-A.C.; Mañes, S. A role for chemokine receptor transactivation in growth factor signaling. EMBO Rep. 2001, 2, 151-156.

128. Toman, R.E.; Payne, S.G.; Watterson, K.R.; Maceyka, M.; Lee, N.H.; Milstien, S.; Bigbee, J.W.; Spiegel, S. Differential transactivation of sphingosine-1-phosphate receptors modulates NGF-induced neurite extension. J. Cell Biol. 2004, 166, 381-392.

129. El-Shewy, H.M.; Johnson, K.R.; Lee, M.H.; Jaffa, A.A.; Obeid, L.M.; Luttrell, L.M. Insulin-like growth factors mediate heterotrimeric $\mathrm{G}$ protein-dependent ERK1/2 activation by transactivating sphingosine 1-phosphate receptors. J. Biol. Chem. 2006, 281, 31399-31407.

130. Delcourt, N.; Bockaert, J.; Marin, P. GPCR-jacking: From a new route in RTK signalling to a new concept in GPCR activation. Trends Pharmacol. Sci. 2007, 28, 602-607. 
131. Valiquette, M.; Parent, S.; Loisel, T.P.; Bouvier, M. Mutation of tyrosine-141 inhibits insulin-promoted tyrosine phosphorylation and increased responsiveness of the human $\beta 2$-adrenergic receptor. EMBO J. 1995, 14, 5542-5549.

132. Baltensperger, K.; Karoor, V.; Paul, H.; Ruoho, A.; Czech, M.P.; Malbon, C.C. The $\beta$-adrenergic receptor is a substrate for the insulin receptor tyrosine kinase. J. Biol. Chem. 1996, 271, 1061-1064.

133. Doronin, S.; Shumay, E.; Wang, H.Y.; Malbon, C.C. Akt mediates sequestration of the $\beta 2$-adrenergic receptor in response to insulin. J. Biol. Chem. 2002, 277, 15124-15131.

134. Gavi, S.; Yin, D.; Shumay, E.; Wang, H.Y.; Malbon, C.C. The 15-amino acid motif of the C terminus of the $\beta_{2}$-adrenergic receptor is sufficient to confer insulin-stimulated counterregulation to the $\beta_{1}$-adrenergic receptor. Endocrinology 2005, 146, 450-457.

135. Karoor, V.; Malbon, C.C. Insulin-like growth factor receptor-1 stimulates phosphorylation of the $\beta_{2}$-adrenergic receptor in vivo on sites distinct from those phosphorylated in response to insulin. J. Biol. Chem. 1996, 271, 29347-29352.

136. García-Sáinz, J.A.; Romero-Ávila, M.T.; Molina-Munoz, T.; García-Pasquel, M.-J. G-protein-coupled receptor-receptor tyrosine kinase crosstalk. Regulation of receptor sensitivity and roles of autocrine feedback loops and signal integration. Curr. Signal. Transduct. Ther. 2008, 3, 174-182.

137. Molina-Muñoz, T.; Romero-Ávila, M.T.; García-Sáinz, J.A. Insulin-like growth factor-I induces $\alpha_{1 \mathrm{~B}}$-adrenergic receptor phosphorylation through $\mathrm{G} \beta \gamma$ and epidermal growth factor receptor transactivation. Mol. Endocrinol. 2006, 20, 2773-2783.

138. Pyne, N.J.; Waters, C.M.; Long, J.S.; Moughal, N.A. ;Tigyi, G.; Pyne, S. Receptor tyrosine kinase-G-protein coupled receptor complex signaling in mammalian cells. Adv. Enzym. Regul. 2007, 47, 271-280.

(C) 2014 by the authors; licensee MDPI, Basel, Switzerland. This article is an open access article distributed under the terms and conditions of the Creative Commons Attribution license (http://creativecommons.org/licenses/by/4.0/). 